\title{
Carbon Nanocomposite Catalysts for Oxygen Reduction and Evolution Reactions: from Nitrogen Doping to Transition-Metal Addition
}

\author{
Gang Wu ${ }^{\mathrm{a}, *}$ Ana Santandreu, ${ }^{\mathrm{a}}$ William Kellogg, ${ }^{\mathrm{a}}$ Shiva Gupta, ${ }^{\mathrm{a}}$ Ogechi Ogoke, ${ }^{\mathrm{a}}$ \\ Hanguang Zhang, ${ }^{\mathrm{a}}$ Hsing-Lin Wang, ${ }^{\mathrm{b}, *}$ and Liming Dai $^{\mathrm{c}, *}$
}


Abstract: Oxygen reduction reaction (ORR) and evolution reaction (OER) is one pair of the most important electrochemical reactions associated with energy conversion and storage technologies, such as fuel cells, metal-air batteries, and water electrolyzers. However, the sluggish ORR and OER requires a significantly large quantity of precious metals (e.g., Pt or Ir) to enhance reaction activity and durability. Highly active and robust nonprecious metal catalysts (NPMC) are desperately required to address the cost and durability issues. Among NPMC formulations studied, carbon-based catalysts hold the greatest promise to replace these precious metals in the future due to their low-cost, extremely high surface area, excellent mechanical and electrical properties, sufficient stability under harsh environments, and high functionality. In particular, nitrogen-doped carbon nanocomposites, which were prepared from "metal-free" N-C formulations and transition metals-derived M-N-C (M=Fe or Co), have demonstrated remarkably improved catalytic activity and stability in alkaline and acidic electrolytes. In this review, based on the recent progress in the field, we aim to provide an overview for both types of carbon catalysts in terms of catalyst synthesis, structure/morphology, and catalytic activity and durability enhancement. We primarily focus on elucidation of synthesis-structure-activity correlations obtained from synthesis and extensive characterization, thereby providing guidance for rational design of advanced catalysts for the ORR. Additionally, a hybrid concept of using highly ORR active carbon nanocomposites to support Pt nanoparticles was highlighted with an aim to enhance catalytic performance and reduce required precious metal loading. Beyond the ORR, opportunities and challenges of ORR/OER bifunctional carbon composite catalysts were outlined. Perspectives on these carbon-based catalysts, future approaches, and possible pathways to address current remaining challenges are also discussed.

.Keywords: Oxygen reduction; oxygen evolution, energy conversion; carbon; nitrogen doping; transition-metal doping 


\section{Introduction}

\subsection{Significance of Electrocatalysis for Oxygen Reduction}

The dominance of fossil fuels as today's energy source has led to increasing concerns about global climate change and national energy security. Large-scale deployment of renewable energy and the electrification of transportation offer an indispensable strategy for addressing these issues [1]. Among available renewable energy sources, solar and wind are the most abundant and readily accessible [2]. However, the distributed and intermittent nature of such renewable energy resources presents a formidable challenge toward their effective utilization [3]. Energy conversion and storage of renewable energy via direct electrochemical oxidation or/and reduction, such as the oxygen reduction reaction (ORR) and the oxygen evolution reaction (OER), are considered clean, efficient, and economically viable solutions to overcome these problems. This will allow the stored energy to be reliably delivered wherever and whenever it is needed.

As shown in Figure 1 [4], polymer electrolyte fuel cells (PEFCs), metal (Li or Zn)-air batteries, and water electrolyzers are the energy conversion and storage technologies associated with these $\mathrm{O}_{2}$ reactions [5-8]. They offer many advantages over traditional fossil fuel combustion, such as vastly improved overall efficiency, high energy density, and significant reduction of $\mathrm{CO}_{2}$ and other emissions. Among others, PEFCs are highly efficient chemical-toelectrical energy conversion devices that can be used as power sources in electric vehicles, portable, and stationary applications. Fuel cell vehicles (FCVs) in particular have the potential to significantly reduce our dependence on foreign oil [9]. They run on hydrogen gas instead of gasoline lowering harmful emissions that result in environmental pollution and possible climate change [10]. Electric cars powered by hydrogen fuel cells have recently become commercially 
available on the market. However, several challenges including their high cost and insufficient performance durability must be overcome before fuel cell vehicle technologies becomes competitive with conventional gasoline vehicles.

Due to the inherently slow reaction kinetics of the ORR, a significant number of precious metals such as Pt are required as catalysts because of their high activity and durability in both acid and alkaline electrolytes. However, to significantly reduce the cost and realize sustainable development, utilization of Pt must be replaced or significantly reduced in the ORR cathode for fuel cell applications. The development of highly active and stable precious-metal-free catalysts thereby become a very important topic in the field of electrocatalysis [11-15]. Considerable scientific interest exists in the exploration of advanced catalyst designs and synthesis by using earth-abundant elements to mimic the catalytic properties of precious metals. It possesses the potential to provide fundamental knowledge and understanding in the field of chemical catalysis for sustainable and clean energy conversion. 


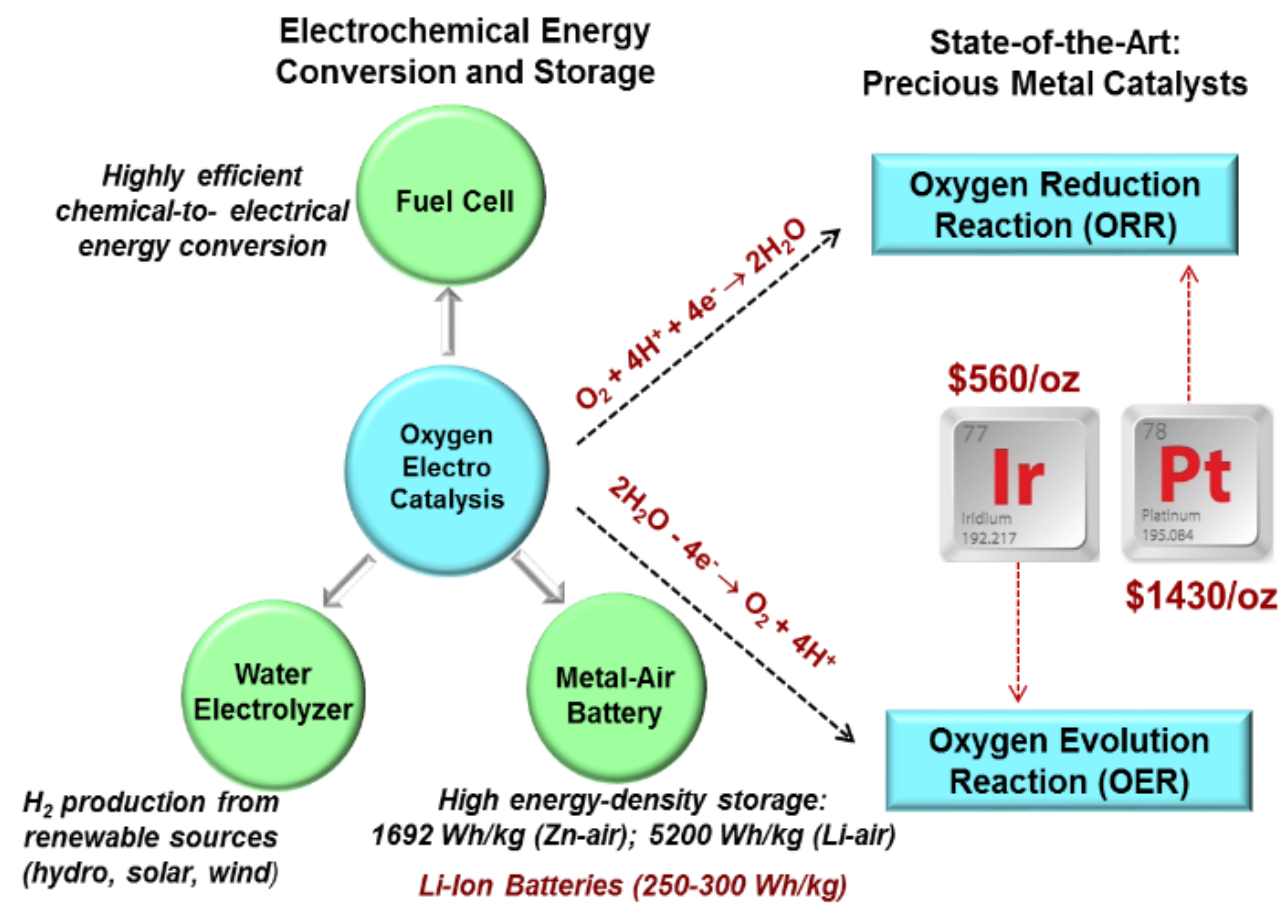

Figure 1. Electrochemical energy conversion relying on oxygen electrocatalysis using precious metal catalysts. Reproduced with permission from Ref [4]. Copyright 2015, Wiley -VCH.

\subsection{Opportunity and Challenges of Nonprecious Metal Electrocatalysis}

During several decades of searching non-precious metal catalysts (NPMCs) for oxygen reduction, significant progress has been made in the areas of synthesis, performance improvement, and mechanism understanding. Compared to other studied catalyst formulations [16-21], carbon nanomaterials, including amorphous carbon blacks, 1D nanotubes, 2D graphene, and 3D mesoporous graphite are promising for NPMC applications because of their low-cost, extremely high surface area, excellent mechanical and electrical properties, sufficient stability under harsh environments, and the easiness to be functionalized [22]. Two types of carbon materials hold great promise to replace Pt in the future for fuel cell and other electrochemical energy application. They are metal-free heteroatom (e.g., N)-doped carbon catalysts (C-N) [14,23-26] and nitrogen- and transition metal-“co-doped" carbon catalysts (M-N-C, M=Fe or/and Co) $[11,23,27-66]$. Generally, decent ORR activity in alkaline media can be achieved on the 
metal-free heteroatom-doped carbon catalysts $[14,23,67]$. Notably, the nitrogen-doped carbon nanotube and graphene catalysts developed by Dai and his coworkers have demonstrated comparable and even better activities to that of Pt catalysts in alkaline media evidenced by rotating disk electrode polarization plots. The microstructure and electronic transport of carbon nanomaterials can be tailored by controlled growth and doping. The substitutional $\mathrm{N}$ atom exhibits $s p^{2}$-like hybridization in C-N bonds. Such $\mathrm{C}-\mathrm{N}$ bonds are considerably polarized owing to the larger electronegativity of nitrogen than carbon; this causes the carbon atoms adjacent to the nitrogen dopants to be positively charged and becomes active sites for $\mathrm{O}_{2}$ adsorption [14]. Although recent studies have also demonstrated good ORR activities for certain metal-free heteroatom-doped carbon catalysts $[17,18]$, the optimal active sites for the ORR in alkaline and acidic environments are likely dissimilar. In this regard, M-N-C catalysts have been more extensively studied for achieving decent ORR activities in more harsh acidic media. In 2009, Lefèvre and Dodelet developed a Fe-based catalyst with significantly increased active sites associated with iron cations coordinated by pyridinic nitrogen functionalities in the interstices of graphitic sheets within the micropores [13]. The current density of a cathode made with the best iron-based electrocatalyst reported can equal that of a Pt-based cathode with a loading of 0.4 $\mathrm{mg} / \mathrm{cm}^{2}$ and at a cell voltage of $\geq 0.9 \mathrm{~V}$. However, due to the possible water flooding in micropore and degradation of the active $\mathrm{FeN}_{4}$ sites, the cathode suffers from significant performance degradation even at relatively low voltages. In 2011, Wu and Zelanav properly selected precursors, designed a synthesis procedure, and produced a Fe-N-C catalyst derived from polyaniline (PANI) and transition metals (Fe or $\mathrm{Co}$ ) that could provide greatly increased density of active sites and strong interaction between active sites and the supporting matrix [11]. The resulting Fe-N-C catalyst was able to minimize the activity gap between $\mathrm{Pt}$ and nonprecious 
metal catalysts to $60 \mathrm{mV}$ in terms of their half-wave potentials $\left(E_{1 / 2}\right)$ of polarization plots in the more challenging acidic electrolyte. In addition to the high activity, the catalyst demonstrated a long-term durability at a voltage of $0.4 \mathrm{~V}$ in a fuel cell. The precise control of the polymer morphology and the interactions among polymer/metal/supports during the thermal decomposition process are the keys to achieving high activity and durability.

Figure 2a and $\mathbf{b}$ show superior activity and durability to $\mathrm{Pt} / \mathrm{C}$ for the best Fe-N-C in alkaline media (0.1 M NaOH). However, in more challenging acid media, NPMCs with Fe-N-C formulations cannot yet provide sufficient activity and performance durability (at high voltage range $>0.6 \mathrm{~V}$ ) for practical acidic Nafion ${ }^{\circledR}$ fuel cell applications. A significant gap between the most active Fe-N-C catalyst and the $\mathrm{Pt} / \mathrm{C}$ in acidic electrolyte must be bridged for viable fuel cell applications (Figure 2c and d) [11]. The onset potentials of the ORR for state-of-the-art Fe-N-C is around $0.95 \pm 0.02 \mathrm{~V}$. This value is still well below the standard potential of $1.23 \mathrm{~V}$ based on thermodynamics. In addition, the most positive half-wave potential, which is governed by the number of active sites i.e. site density $\left(\mathrm{N} / \mathrm{cm}^{2}\right.$ or $\left.\mathrm{N} / \mathrm{mg}\right)$, only reaches $0.80 \pm 0.02 \mathrm{~V}$ vs. RHE. Thus, there is much room left for improvement of Fe-N-C catalysts by optimizing catalyst structures and morphologies with significantly increased active site density. Notable, estabilishment of good standard ORR activities of $\mathrm{Pt} / \mathrm{C}$ reference in both acidic and alkaline electrolytes are important for NPMC research communities as references. As shown in Figure 2, accroding to Zelenay et al.[11,68], et al., in $0.1 \mathrm{M} \mathrm{HClO}_{4}$, the half-wave potential for a $\mathrm{Pt} / \mathrm{C}$ catalsyt at a high precious metal loading of $60 \mu \mathrm{g} \mathrm{cm}^{-2}$ should reach $0.86 \mathrm{~V}$ vs RHE. In $0.1 \mathrm{M}$ $\mathrm{NaOH}$ electrolyte, half-wave potential is around $0.91 \mathrm{~V}$ vs RHE when a higher Pt loading is used at $60 \mu \mathrm{g} \mathrm{cm}^{-2}$. 

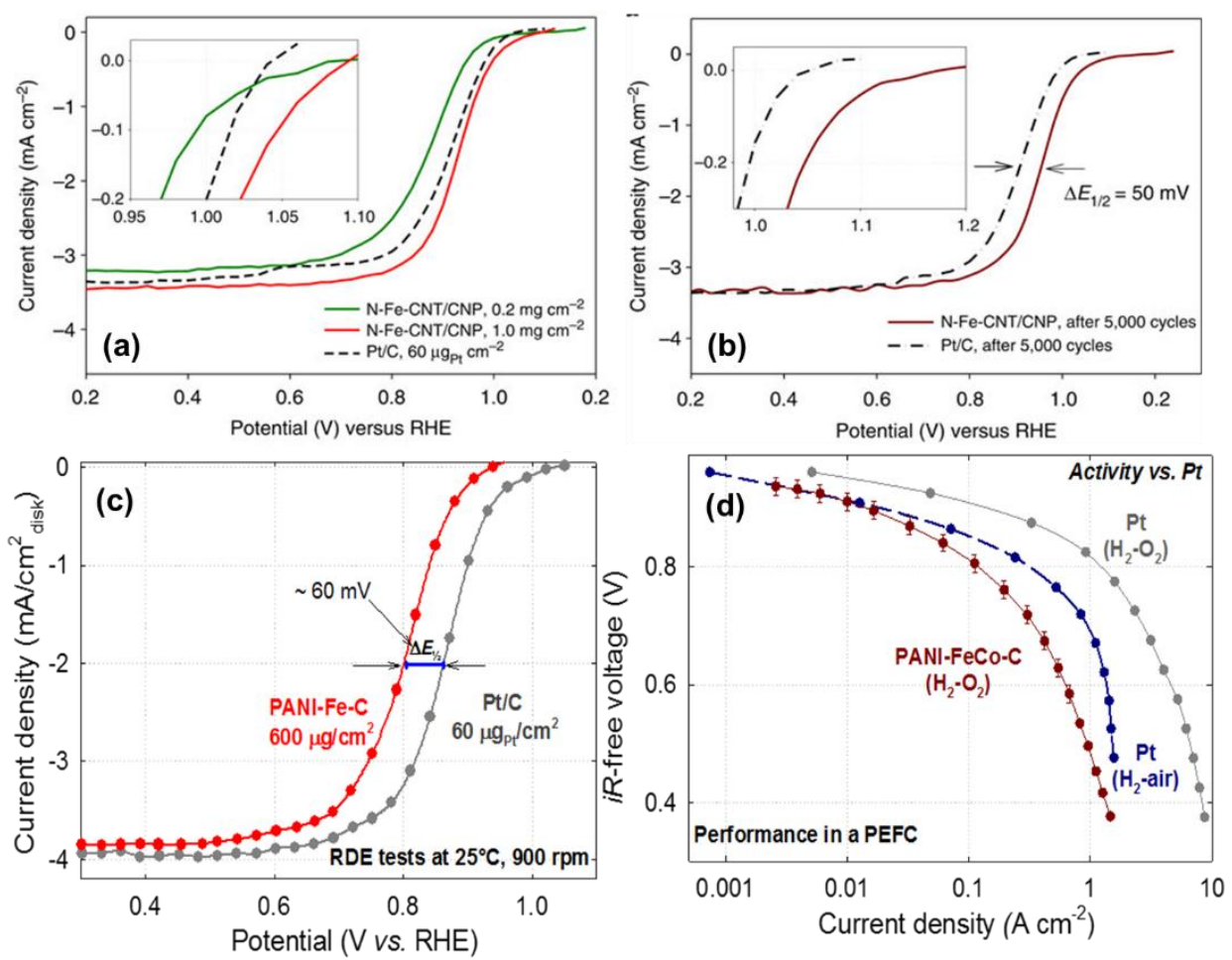

Figure 2. Superior ORR activity (c) and durability (d) in alkaline media $(0.1 \mathrm{M} \mathrm{NaOH})$ was achieved on a $\mathrm{Fe}-\mathrm{N}-\mathrm{C}$ catalyst relative to a Pt/C reference. Reproduced with permission from Ref [68]. Copyright 2013, Macmillan Publishers Ltd. Gaps still need to be bridged between state-of-the-art Fe-N-C and Pt/C catalysts in acidic media described by using RDE (a) and fuel cell performance (b) Reproduced with permission from Ref [11]. Copyright 2011, American Association for the Advancement of Science.

In addition, in the midst of searching for the most active $\mathrm{Pt}$, numerous strategies of controlling Pt alloy structure and morphology have been introduced [69] in order to improve ORR activity compared to individual Pt. For example, the most active fully ordered fctstructured FePt alloy nanoparticle catalyst exhibited a half-wave potential up to $0.958 \mathrm{~V}$ in $0.1 \mathrm{M}$ $\mathrm{HClO}_{4}$ electrolyte when a Pt loading is $45.5 \mu \mathrm{g} \mathrm{cm}^{-2}$ [4], one of the most positive values obtained for ORR catalysis in acid under similar conditions [70-75]. Therefore, development of advanced NPMCs with approaching activity and durability to Pt-based catalysts has been attracting substantial attention in the electrocatalysis society over the past five years.

A current challenge to hinder rational catalsyt design and synthesis is the lack of undersanding of the exact active site in the M-N-C catalysts. The current understanding is only 
qualitative knowledge inferred from understanding of the synthesis processes and based on information from somewhat insensitive characterization techniques. For example, in M-N-C catalysts, carbon is the dominant component (up to 85 at\%) and high levels of graphitic and pyridinic nitrogen (up to 8 at $\%$ ) are successfully doped into the carbon structures to replace the carbon atoms at the inside and the edges of the planes, respectively [44]. Furthermore, there is a possibility that a transition metal (e.g., Fe, up to 5 at\%) cation is able to coordinate with pyridinic nitrogen and embedded itself into the carbon plane as a possible active site configuration [40], which provides enhanced intrinsic ORR activity compared to the metal-free $\mathrm{N}$-doped carbon. However, it is unclear whether the transition metals is the crucial center of the active site(s), or if it only catalyzes the process of nitrogen doping into carbon. The role of the transition metals in the M-N-C catalyst seems still to be controversial. Diversified nanocarbon structures such as tubes, onion-like carbon, and multiple-layered graphene once were observed in highly active MN-C catalysts $[41,43,76,77]$. Initially, we speculated that the in situ formation of highly graphitized nanocarbon in catalysts seemed to be a critical factor dictating active site generation and was directly linked to the observed ORR activity $[40,77]$. In our recent effort to develop the M-N-C catalyst derived from metal organic frameworks (MOFs), dominant amorphous or partially graphitized carbon with uniform distributions of $\mathrm{N}$ and $\mathrm{Fe}$ were found in a new type of Fe-N-C catalyst showing even higher ORR activity ( $E_{1 / 2}$ up to $0.82 \mathrm{~V} v s$ RHE) and stability relative to graphitized nanocarbon-rich Fe-N-C catalysts $(0.80 \mathrm{~V})$. Thus, it seems that the highly graphitized carbon structures in the M-N-C catalysts are not necessary for generating high ORR activity. These puzzles notwithstanding, catalytic activity was to be found to be strongly dependent on the synthetic chemistry of catalysts. Particularly important factors are the structure of the nitrogen-carbon precursor, transition metals, heating conditions, supporting templates, and 
post treatments. In addition, the way to integrate nitrogen, carbon, and metal species is crucial for achieving high activity. As shown in Figure 3 [50,78], in this review, we summarize the new concepts and methods recently developed to prepare highly efficient metal-free and transition metal-derived carbon composite catalysts for oxygen reduction in both alkaline and acidic electrolytes. We focus on elucidating synthesis-structure-property correlations acquired from synthesis processes and extensive characterization. The aim is to provide effective guidance to design and prepare novel carbon nanocomposite catalysts with continuously improved performance.

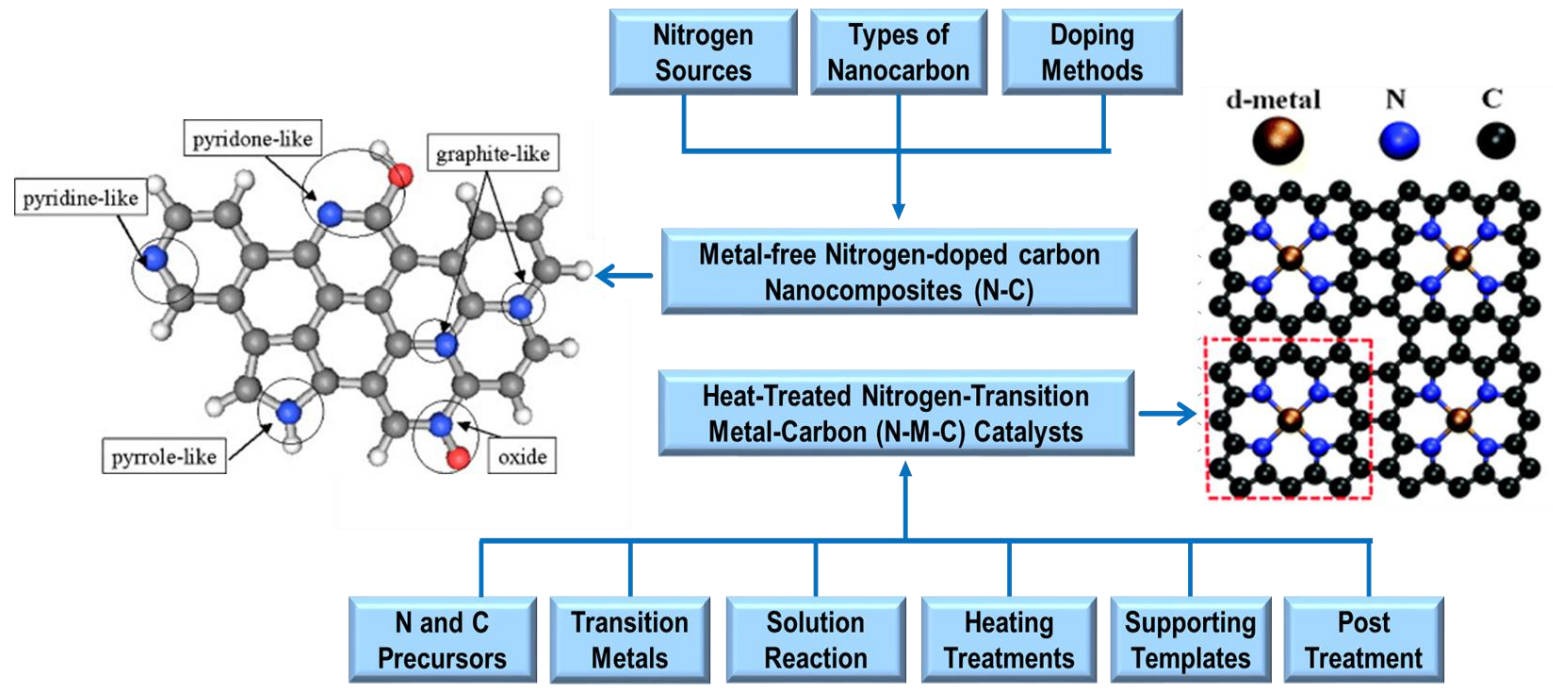

Figure 3. Effect of synthetic parameters on performance of metal-free nitrogen-doped $(\mathrm{N}-\mathrm{C})$ and transition metal-derived carbon (M-N-C) catalysts. Reproduced with permission from Ref. [50,78]. Copyright 2009, Elsevier and copyright 2011, Royal Society of Chemistry.

\section{Nitrogen-doped Carbon Catalysts}

\subsection{Nitrogen Doping}

Compared to other heteroatoms, nitrogen specifically offers significant promise as a nonmetal dopant because one can dope it into several locations within the carbon structure, thus resulting 
in multiple possible configurations $[79,80]$. Being more electronegative than carbon, nitrogen makes neighboring carbon atoms electron deficient, thereby promoting oxygen adsorption on the carbon nanostructure. On the other hand, having one extra valence electron than carbon makes nitrogen a promising n-dopant, which pushes the Fermi level closer to conduction band making the carbon nanostructure more electronically conductive and disordered [67,81]. Moreover, the comparable atomic size of nitrogen and carbon along with five available valence electrons present in nitrogen allow the formation of strong covalent bonds in nitrogen-doped carbon and thus increasing its stability [82]. Oxygen adsorption may then occur at the resulting defect sites within the graphene edges or in the basal plane. Earlier studies have demonstrated nitrogen edge doping and general edge structure can utilize a four-electron pathway to notably improve ORR activity $[80,83,84]$.

Generally, doped nitrogen atoms in carbon planes can be primarily divided into three types as shown in Figure 4a [85]. XPS typically is used to distinguish these doped nitrogen atoms according to their corresponding binding energies (Figure 4b) [37]. Among various nitrogendoping positions, pyridinic nitrogen that is located at the edge sites just possesses two $\mathrm{sp}^{2}$ carbons. Therefore, it only provides the graphitic $\pi$ system with one $\mathrm{p}_{\boldsymbol{\pi}}$ electron. In-plane graphitic nitrogen is able to provide two $p_{\pi}$ electrons. The pyrrolic nitrogen atom in the fivesided ring is thermally unstable and could convert into a graphitic nitrogen atom inside the graphitic carbon plane when the heating temperature is above $800^{\circ} \mathrm{C}$ [41]. Lahaye et al. [86] verified the higher surface polarity of nitrogen doped carbons compared to carbons lacking any nitrogen doping. This result proves that graphitic layers doped with nitrogen demonstrate quicker charge transfer rates than pure carbon black at the double layer $[87,88]$, and thus improve the transfer of protons and electrons for the ORR. In principles, these studies show how precise 
nitrogen doping allows one to tailor a catalyst's structure-property relationship and thus improve its activity for the ORR. However, it is not possible to completely control nitrogen-doping sites in carbon nanomaterials, but precise use of nitrogen-containing precursors during synthesis has led to the development of nitrogen-doped structures such as graphene and carbon nanotubes with optimal dopants, which have exhibited highly improved ORR activity, relative to undoped nanocarbons.
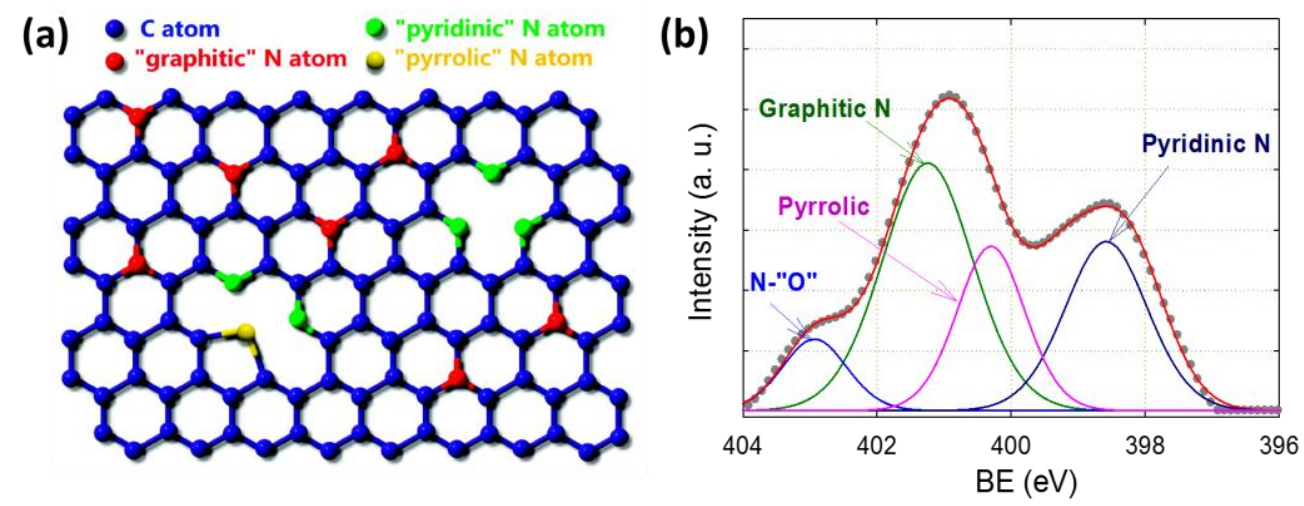

Figure 4 (a) Nitrogen doping into carbon plane at different location. Reproduced with permission from Ref. [85]. Copyright 2009, American Chemical Society. (b) Typical binding energies of nitrogen atoms in different doping environment determined by X-ray photoelectron spectroscopy. Reproduced with permission from Ref [37]. Copyright 2011, Royal Society of Chemistry.

\subsection{Nitrogen-doped Carbon Nanotube Catalysts}

Carbon nanotubes (CNTs) have been the subject of studies for over 20 years, and research has found they possess several significant advantages compared to carbon blacks for usage as electrocatalysts in fuel cells. These include but are not limited to heightened mass transfer, improved electronic conductivity, and greater corrosion resistance [89-92]. Recent syntheses of vertically aligned N-CNTs (Figure 5a) were able to produce ORR activity comparable to that of $\mathrm{Pt} / \mathrm{C}$ catalysts in alkaline media (Figure 5b) [14]. 

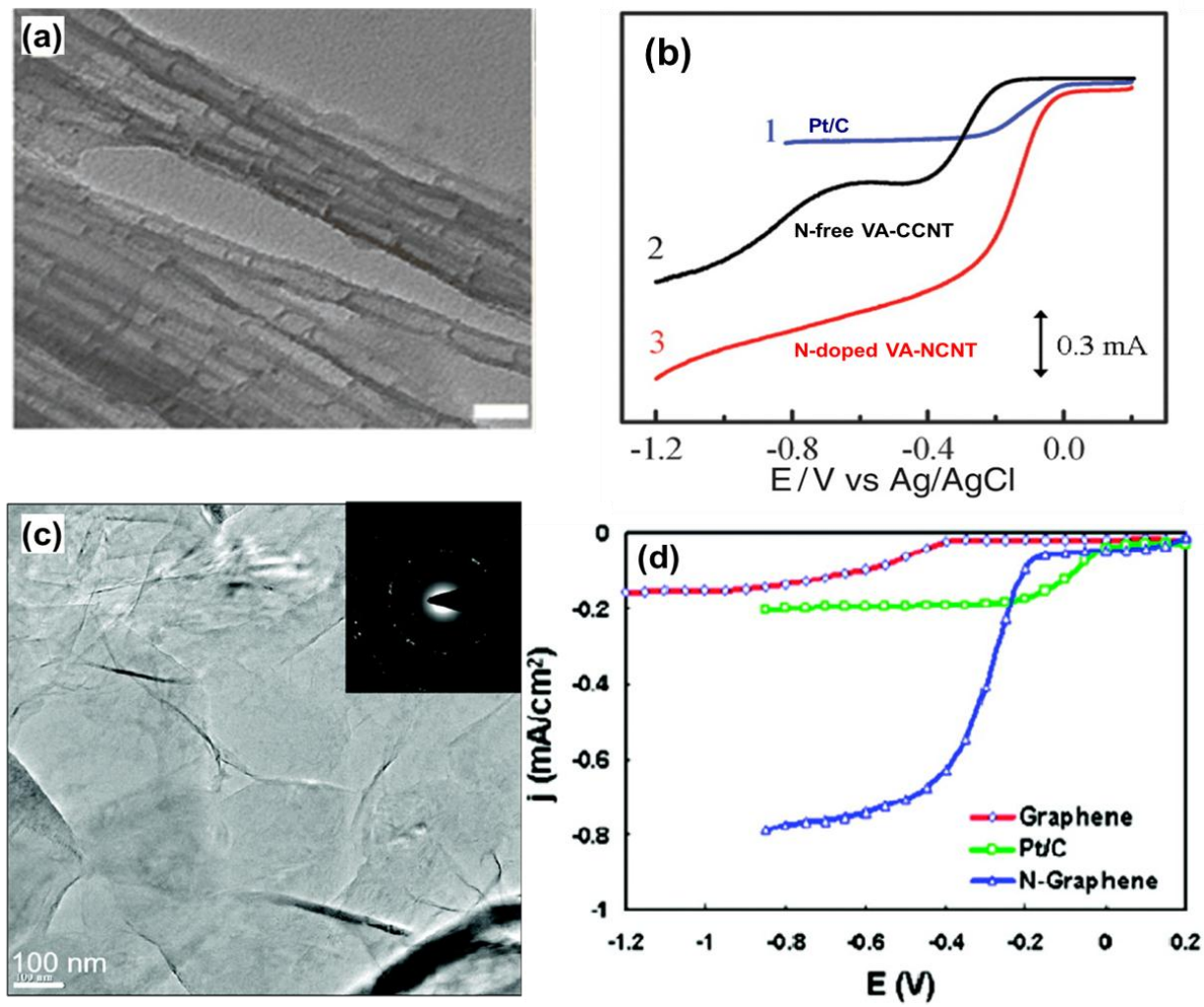

Figure 5. Morphology (a) and ORR activity (b) in $0.1 \mathrm{M} \mathrm{KOH}$ for vertical aligned (VA) nitrogen-doped carbon nanotube catalysts (NCNT) and other controls at a scan rate of $10 \mathrm{mVs}^{-1}$. Reproduced with permission from Ref. [14]. Copyright 2011, American Association for the Advancement of Science. A TEM image (c) and ORR activity comparison in $0.1 \mathrm{M} \mathrm{KOH} \mathrm{(d)} \mathrm{for} \mathrm{graphene,} \mathrm{nitrogen-doped} \mathrm{graphene,}$ and $\mathrm{Pt} / \mathrm{C}$ catalysts. Electrode rotating rate: $1000 \mathrm{rpm}$. Scan rate: $10 \mathrm{mVs}^{-1}$. Electrode loadings: $\operatorname{mass}_{(\text {graphene })}=\operatorname{mass}_{(\mathrm{P} / \mathrm{C})}=\operatorname{mass}_{(\mathrm{N} \text {-grapene })}=7.5 \mu \mathrm{g}$. Reproduced with permission from Ref. [23]. Copyright 2010, American Chemical Society.

It should be noted that, unlike the nitrogen-free CNT electrode, the nitrogen-doped carbon nanotube (NCNT) electrode exhibited a one-step process for the ORR with a steady-state diffusion current that was almost twice that obtained at the CNT electrode. Furthermore, compared with the non-aligned NCNT electrode, the enhanced ORR activity observed with the vertical aligned NCNT (VA-NCNT) electrode can be attributed to its well-defined large surface area with all of the nanotube top-ends falling on one plane at the interface between the aligned nanotube electrode and electrolyte solution to further improve the electrolyte/reactant diffusion 
[14]. Due to the facilitated mass transfer and increased surface areas within the catalyst layer, a larger limiting current density was observed with the VA-NCNT electrode. The charge delocalization induced by $\mathrm{N}$-doping was found to impair $\mathrm{O}-\mathrm{O}$ bonding because it promoted oxygen chemisorption onto the N-CNTs (Yeager or bridge model) over end-on adsorption (Pauling model). Further studies were then carried out to compare electronic structure properties of N-CNTs to pure CNTs via a density functional theory [93]. Several descriptors were evaluated in terms of their ability to predict external surface reactivity of carbon/nitrogen. Electrostatic potential along with average local ionization energy upon the nanotube surfaces was determined to be the most indicative [94].

Pyridinic and graphitic nitrogen have been extensively investigated in terms of their promotional roles in enhancing ORR activity on carbon catalysts. These nitrogen dopings noticeably alter distribution of potential and electronic environment for the pristine CNT and graphene, and the specific placement of the doping sites is significant. Sharifi et. al conducted studies to specifically understand the role nitrogen doped functionalities play for the N-CNT with respect to the ORR [95]. The pyridinic nitrogen locating at the edge of carbon planes is widely considered as active sites to adsorb $\mathrm{O}_{2}$. The pyridinic sites could associated with the number of active sites for the ORR via a four-electron pathway. Ishikawa et al., prepared a series of vertically aligned carbon nanotubes with a surface nitrogen concentration of $0,4.3,5.6,8.4$, and 10.7 atom $\%$ by the alumina template technique [96]. The measured electrocatalytic ORR activity determined by half-wave potential is linearly increased with the content of pyridinictype nitrogen sites [96]. This work provided an evidence that the active site in the N-doped carbon nanotube catalysts for the ORR is associated with the pyridinic-type nitrogen sites. However, graphitic nitrogen sites could be also important to the ORR through modifying 
electronic structures of carbon planes, while they only catalyze via a peroxide intermediate and a two-electron pathway [94]. This information can aid further studies and applications of N-CNTs as metal-free catalysts.

\subsection{Nitrogen-doped Graphene Catalysts}

Graphene, the foundational structure for all graphitic carbons, is a single atom thick twodimensional sheet of $\mathrm{sp}^{2}$ carbons bonded into a hexagonal lattice. Graphene's basal plane structure, chemical stability, theoretical surface area $\left(2630 \mathrm{~m}^{2} \mathrm{~g}^{-1}\right)$, conductivity, and its ease to functionalization all make it an attractive candidate as an ORR catalyst [23,97,98]. Dai and coworkers developed an nitrogen-doped graphene (N-G) catalyst to function as a metal-free ORR catalyst in alkaline media [23]. The N-doped graphene film (Figure 5c) was prepared by a nitrogen-containing reaction gas mixture and a $\mathrm{Ni}$-coated $\mathrm{SiO}_{2} / \mathrm{Si}$ substrate with $\mathrm{Ni}$ as a catalyst [23]. This catalyst showed impressive electrocatalytic properties toward the ORR (Figure 5d), further demonstrating the importance of nitrogen doping in advanced carbon materials. Numerous N-G catalysts synthesis methods have been discovered and developed since this pioneering work. For example, nitrogen plasma has been utilized during synthesis of N-G catalysts via a physical method to produce high ORR activity [98]. Table 1 provides a summary of N-G catalysts including their synthesis methods and applications. 
Table 1. Summary of nitrogen-doped graphene catalysts

\begin{tabular}{|c|c|c|c|c|}
\hline method & precursors & doping structure & doping level & applications, refs \\
\hline \multirow{5}{*}{$\begin{array}{l}\text { Thermal } \\
\text { annealing }\end{array}$} & $\mathrm{GO}, \mathrm{NH}_{3}$ & $\begin{array}{l}\text { pyridinic, pyrrolic, } \\
\text { graphitic } \mathrm{N}\end{array}$ & $5 \%$ & [99] \\
\hline & $\begin{array}{c}\mathrm{Ni}(\mathrm{C}) / \mathrm{B}(\mathrm{N}) / \mathrm{SiO} \\
{ }_{2} / \mathrm{Si} \text { substrate }\end{array}$ & $\begin{array}{l}\text { pyridinic, pyrrolic, } \\
\text { graphitic } \mathrm{N}\end{array}$ & $\begin{array}{c}0.3-2.9 \mathrm{~N} / \mathrm{C} \text { at. } \\
\%\end{array}$ & {$[100]$} \\
\hline & $\begin{array}{c}\text { 3D NGF: GO, } 5 \\
\text { vol \% pyrrole }\end{array}$ & pyridinic, pyrrolic $\mathrm{N}$ & 4.2 at. $\%$ & ORR [101] \\
\hline & Sugar and urea & $\begin{array}{l}\text { pyridinic, pyrrolic, } \\
\text { graphitic } \mathrm{N}, \mathrm{N} \text { oxide }\end{array}$ & $3.02-11.2$ at. $\%$ & ORR[102] \\
\hline & $\begin{array}{c}\text { GO, copper } \\
\text { amine complex }\end{array}$ & $\begin{array}{l}\text { pyridinic, pyrrolic, } \\
\text { graphitic N, N oxide }\end{array}$ & $2.85-2.45$ at. $\%$ & ORR[103] \\
\hline \multirow{7}{*}{ CVD } & pyridine & $\begin{array}{c}\text { pyridinic, graphitic } \\
\text { N }\end{array}$ & 2.4 at. $\%$ & [104] \\
\hline & $\mathrm{CH}_{4}$ on $\mathrm{Ni}$ foil & $\mathrm{NH}_{3}$ & 4 at. $\%$ & ORR[16] \\
\hline & $\begin{array}{c}\mathrm{H}_{2}, \mathrm{C}_{2} \mathrm{H}_{4}, \mathrm{NH}_{3} \\
\text { on } \mathrm{Cu} \text { foils }\end{array}$ & pure pyridinic $\mathrm{N}$ & 16 at. $\%$ & ORR[105] \\
\hline & $\begin{array}{l}\mathrm{CH}_{4}, \mathrm{NH}_{3} \text {, on } \\
\mathrm{Cu} \text { foils }\end{array}$ & $\begin{array}{l}\text { pyridinic, pyrrolic, } \\
\text { graphitic } \mathrm{N}\end{array}$ & 8.9 at. $\%$ & {$[85]$} \\
\hline & $\begin{array}{l}\text { triazine on a } \\
\text { Ni(111) film }\end{array}$ & $\begin{array}{c}\text { pyridinic, } 80 \% \\
\text { graphitic } \mathrm{N}\end{array}$ & $1-2$ at. $\%$ & {$[106]$} \\
\hline & $\begin{array}{c}\mathrm{CH}_{4} \mathrm{H}_{2} \mathrm{NH}_{3} \text { on } \\
\mathrm{Cu} \text { foils }\end{array}$ & graphitic $\mathrm{N}$ & $\begin{array}{c}0.23-0.35 \mathrm{~N} / \mathrm{C} \\
\text { at. } \%\end{array}$ & {$[107]$} \\
\hline & pyridine & & 16.7 at. $\%$ & [108] \\
\hline \multirow{3}{*}{$\begin{array}{l}\text { solvothermal } \\
\text { synthesis }\end{array}$} & $\mathrm{GO}, \mathrm{N}_{2} \mathrm{H}_{4}, \mathrm{NH}_{3}$ & $\begin{array}{c}\text { pyridinic, pyrrolic, } \\
\text { graphitic, pyridinic } \\
\mathrm{N} \text { oxides }\end{array}$ & $5 \mathrm{wt} \%$ & [109] \\
\hline & $\mathrm{GO}$, urea & $\begin{array}{c}\text { pyridinic, pyrrolic, } \\
\text { graphitic } \mathrm{N}\end{array}$ & 10.13 at. $\%$ & $\begin{array}{c}\text { Capacitive } \\
\text { behaviors[110] }\end{array}$ \\
\hline & $\mathrm{CCl}_{4}, \mathrm{LiN}$ & $\begin{array}{l}\text { pyridinic, pyrrolic, } \\
\text { graphitic N }\end{array}$ & $16.4 \% \mathrm{~N} / \mathrm{C}$ & {$[111]$} \\
\hline $\begin{array}{l}\text { supercritical } \\
\text { reaction }\end{array}$ & $\begin{array}{c}\text { graphite, } \\
\text { acetonitrile }\end{array}$ & $\begin{array}{l}\text { pyridinic, pyrrolic, } \\
\text { graphitic N }\end{array}$ & $1.57-4.56$ at. $\%$ & {$[112]$} \\
\hline arc discharge & $\begin{array}{c}\text { graphite, } \\
\text { pyridine/ammo } \\
\text { nia }\end{array}$ & $\begin{array}{c}\text { pyridinic, graphitic } \\
\mathrm{N}\end{array}$ & $0.6-1.4$ at. $\%$ & [113] \\
\hline plasma & $\begin{array}{l}\text { graphene, } \\
\text { nitrogen plasma }\end{array}$ & $\begin{array}{c}\text { pyridinic, pyrrolic, } \\
\text { graphitic, pyridinic } \\
\mathrm{N} \text { oxides }\end{array}$ & 8.5 at. $\%$ & [98] \\
\hline $\begin{array}{c}\text { nitrogen } \\
\text { bombardmen } \\
\mathrm{t}\end{array}$ & $\begin{array}{l}\text { graphene on } \\
\quad \mathrm{Ni}(111)\end{array}$ & $\begin{array}{c}\text { pyridinic, graphitic } \\
\mathrm{N}\end{array}$ & & {$[114]$} \\
\hline
\end{tabular}




\begin{tabular}{l|llll}
\hline ball-milling & graphite in $\mathrm{N}_{2}$ & pyridinic, pyrrolic $\mathrm{N}$ & $14.84 \mathrm{wt} \%$
\end{tabular}

A major component in graphene preparation, graphene oxide (GO) has attracted extensive attention. GO is commonly prepared by oxidizing graphite powder in severe chemical conditions. Oxygen-containing functional groups, including epoxy, carboxyl and hydroxyl, are then functionalized onto each side of the sheet [116]. Coulombic repulsion present between the functional groups allows GO flakes to form single or multi-layered sheets, which are highly soluble in water. One can obtain highly electrically conductive graphene materials with a repaired $\boldsymbol{\pi}$-conjugated structure from $\mathrm{GO}$ after the completion of a reduction process $[30,41,117]$. Therefore, GO shows significant promise as a graphene material that can utilize its reduction process to effectively tune and control its vacancies and defects. Recent large-scale synthesis efforts have used cyanamide in combination with thermal annealing to create N-G with nitrogen content of up to $12 \%$ [44]. Briefly, first, $\mathrm{CN}-\mathrm{G}$ composites were generated from the annealing at $550^{\circ} \mathrm{C}$ of $\mathrm{GO}$ functionalized by sodium dodecylbenzensulfonic acid and cyanamide. Second, CN decomposition occurred and ultimately produced N-G after CN-G heat treatment at $900^{\circ} \mathrm{C}$. The final N-G catalyst outperforms commercial Pt/C catalysts in alkaline media with regards to their methanol tolerance, catalyst durability ( $87 \%$ post 10,000 cycles), and kinetic current density (6.67 $\mathrm{mA} \mathrm{cm}^{-2}$, at $\left.-0.4 \mathrm{~V} v s . \mathrm{Ag} / \mathrm{AgCl}\right)$ [94]. Graphitic nitrogen content was found to influence electrochemical performance more significantly than pyridinic nitrogen content. This results are opposite to those obtained from N-doped CNT catalysts indicating pyridinic $\mathrm{N}$ is directly correlated to ORR activity [96]. Thus, the role of doped nitrogen could be dependent on structures of nanocarbon, for example, close tubes $v s$. opening plane sheets. 
More importantly, this nitrogen content type can be tailored by using different nitrogen precursors in the N-G synthesis. As shown in Figure 6, Lai et al., annealed various nitrogen species such as ammonia, polypyrrole (PPy) and polyaniline (PANI) with GO to further study the connections between precursor, nitrogen doping, and catalytic activity [46]. The ammonia/GO primarily generated graphitic and pyridinic nitrogen centers while PANI/GO mostly produced pyridinic moieties, and PPy/GO mainly created pyrrolic moieties. In good agreement with others, total nitrogen doesn't directly link to measured activity and pyridinic and graphitic nitrogen atoms were found important. Especially, they indicated that, pyridinic nitrogen content shifted the ORR onset potential to more positive, whereas higher graphitic nitrogen content lead to a conversion of ORR reaction mechanism from a two-electron pathway to fourelectron one [46]. However, these conclusions are still debatable. Previous studies suggested graphitic $\mathrm{N}$ affect overall electron distribution on carbon, thereby governing the activation energy and determining the onset potentials. On the other hand, pyridinic $\mathrm{N}$ is linked to active sites and affects the number of active sites. 


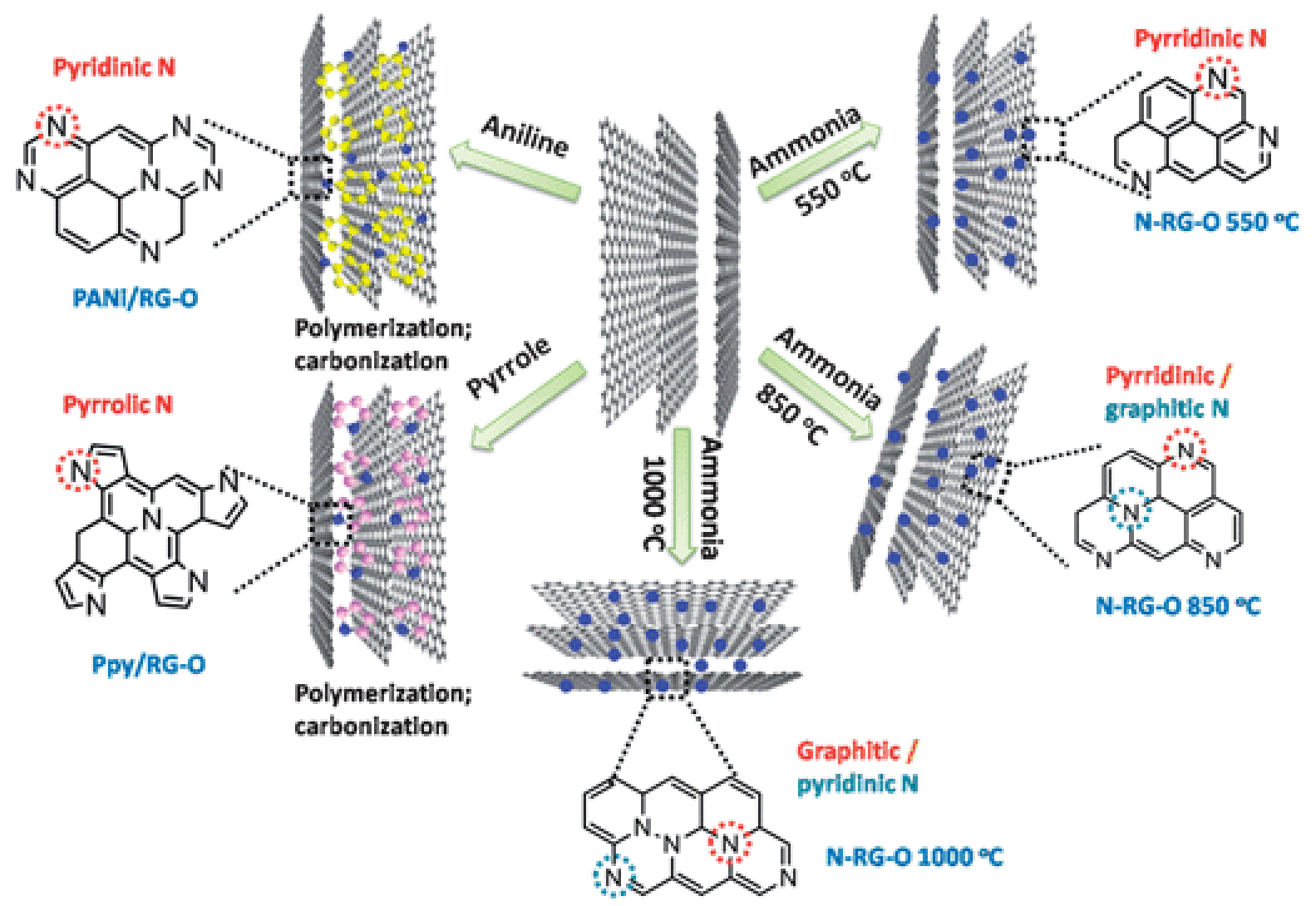

Figure 6. Schematic diagram for preparation of $\mathrm{N}$-doped reduced graphene oxide (graphene) with different $\mathrm{N}$ states. N-RG-O 550, 850, and $1000{ }^{\circ} \mathrm{C}$ are prepared by annealing of $\mathrm{GO}$ powder at temperatures of 550,850 , and $1000^{\circ} \mathrm{C}$ under a $\mathrm{NH}_{3}$-atmosphere. PANI/RG-O and PPy/rGO are prepared by annealing of PANII/GO and PPy/GO composites at $850{ }^{\circ} \mathrm{C}$. Reproduced with permission from Ref. [46]. Copyright 2011, Royal Society of Chemistry

Generally, carbon electrode (e.g., GC)exhibits relatively low 4-electron selectivity during the ORR and generates high peroxide yields, but this will greatly depend on carbon structure (e.g., morphology and graphitization degree) and nitrogen doping (e.g., total nitrogen content, doping position, ratios of various nitrogen such as pyridinic, pyrrolic, or graphitic $\mathrm{N}$ ) [118]. We have also discovered that an increased degree of graphitization in carbon leads to reduced peroxide yield [34]. It was found that pyrrolic nitrogen sites within the carbon material might indeed lead to a two-electron process during the ORR [119], which can be reduced by a higher heating treatment $\left(>1000{ }^{\circ} \mathrm{C}\right)$. In addition, an increased nitrogen content may favor the two-electron 
process [120]. Therefore, properly designed nanocarbon architecture with proper nitrogen doping is able to mitigate the peroxide yields though direct $4 \mathrm{e}^{-}$and/or $2 \mathrm{e}^{-}+2 \mathrm{e}^{-}$pathways. Figure $5 \mathrm{~b}$ demonstrates that the nitrogen-doped vertically aligned CNT catalyst is able to exceptionally improve 4-electron selectivity when compared to nitrogen-free CNT [14]. On the other hand, this also opens a possibility for the development of efficient electrocatalysts for a pure two-electron process for peroxide generation using carbon electrodes.

\subsection{Nitrogen-doped Graphene/Carbon-Nanotube Composite Catalysts}

Since N-G and N-CNT catalysts have each shown promising ORR activity, some interest has sprouted up to develop new advanced carbon catalysts with the best aspects of both structures [121]. Recently, Xia et al., utilized a low temperature $\left(180^{\circ} \mathrm{C}\right)$ hydrothermal process with oxidized carbon nanotubes (OCNT), GO, and ammonia as precursors to synthesize a N-G and CNT nanocomposite catalyst [30]. In $0.1 \mathrm{M} \mathrm{KOH}$, the nanocomposite catalyst demonstrated improved onset potential and higher limiting current for the ORR when compared to individual CNTs, N-G and nitrogen containing CNTs, and a physical mixture of graphene oxide and oxidized CNTs. The determined synergistic effect that likely exists between graphene and CNTs was further verified by in-situ growing nitrogen-doped nanotube and graphene composites. As shown in Figure 7, Wei et al., reported a nitrogen doped single-walled carbon nanotube (SWNT)/graphene composite as an efficient electrocatalyst. The in situ growth simultaneously lead to graphene and SWCNT with nitrogen doping, generating a three dimensional interconnected network with a high surface area of $812.9 \mathrm{~m}^{2} \mathrm{~g}^{-1}$ and high electrical conductivity of $53.8 \mathrm{Scm}^{-1}$. Nitrogen doping was well-dispersed into both graphene and SWCNT, but at a relatively low level $(0.53$ at $\%)$. A high ORR activity in alkaline media was measured by the 
authors, which was much superior to two constituent components and even comparable to the commercial $20 \mathrm{wt} \% \mathrm{Pt} / \mathrm{C}$ catalysts [122].

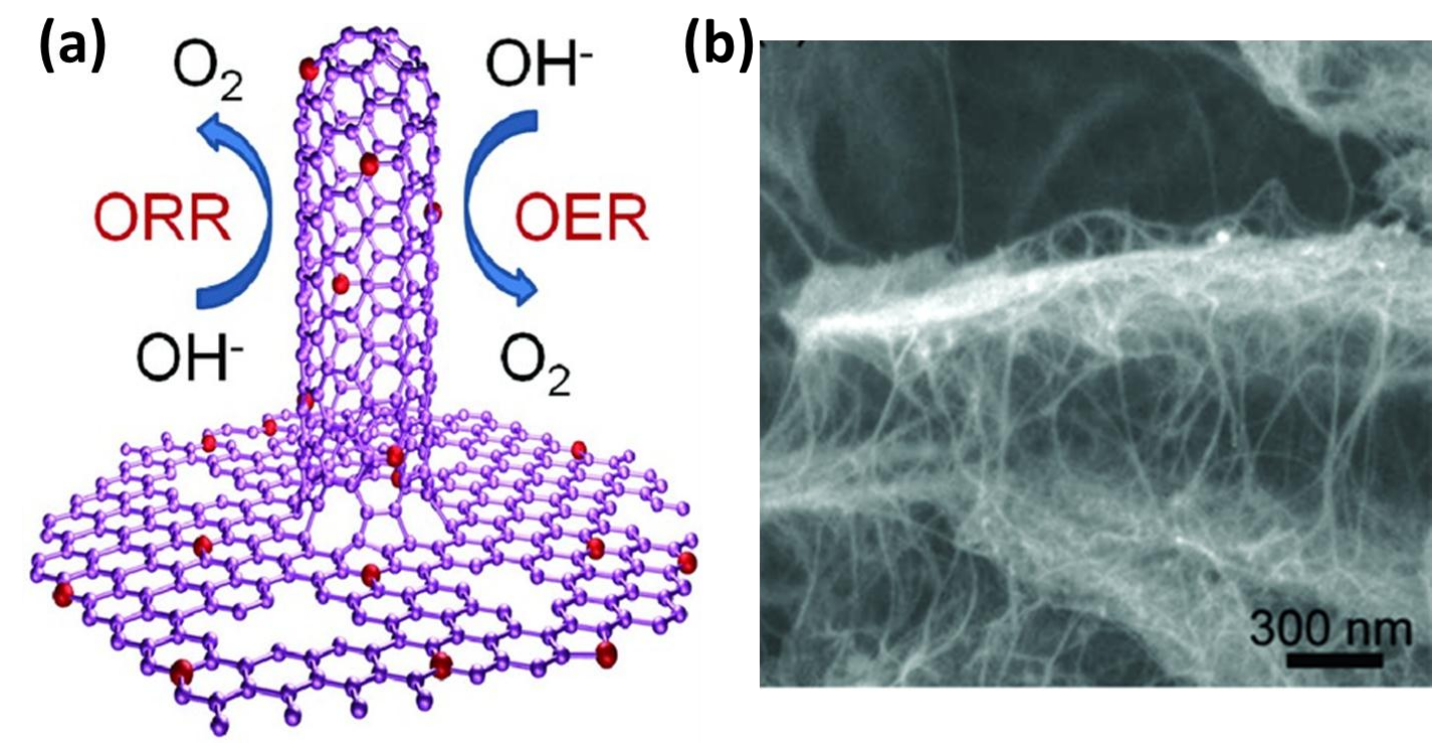

Figure 7. One step growth of nitrogen doped graphene/carbon nanotube composite catalyst (a) and a typical SEM image (b). Reproduced with permission from Ref. [122]. Copyright 2014, Wiley -VCH.

Other heteroatoms such as boron-, sulfur- and phosphorous-doped carbon materials also have been studied in terms of their catalytic activity for the ORR. It is of fundamental importance to explore such heteroatom doping and to understand their effects on changes of electronic and geometric structure of carbons. However, no significantly additional benefit was obtained so far to further improve ORR activity and durability by doping these heteroatoms beyond nitrogen. Therefore, these heteroatom-doped carbon catalysts are not covered in this review. The relevant information can be found from other review articles $[25,67]$.

It should be noted that due to the improved ORR activity measured with these nitrogen-doped carbon catalysts in alkaline and nonaqueous electrolytes, they could be very useful in alkaline fuel cells, Zn-air batteries, and nonaqueous Li-air batteries [32,94]. For example, the Zn-air 
battery is a very important energy storage device as an alternative to electrify EVs in the future. Highly concentrated potassium hydroxide solution (e.g., $6.0 \mathrm{M} \mathrm{KOH})$ is commonly used as the electrolyte in batteries. These highly active nitrogen-doped carbon composites in alkaline media will be good candidates for ORR active constitutes in air cathodes. For instance, the ORR-active nitrogen-doped carbon nanotubes (NCNTs) were used as a structural support for OER-active lanthanum nickelate $\left(\mathrm{LaNiO}_{3}\right)$ in a shell-core structured configuration in alkaline media, they demonstrated a synergistic effect and lead to excellent performance in rechargeable $\mathrm{Zn}$-air batteries [123]. In addition, nitrogen-doped graphene nanosheets (N-GNSs) were prepared by post heating graphene sheets under high purity ammonia mixed with $\mathrm{Ar}$ at $900{ }^{\circ} \mathrm{C}$ for $5 \mathrm{~min}$. As a potential cathode for $\mathrm{Li}^{-\mathrm{O}_{2}}$ batteries with $0.1 \mathrm{M} \mathrm{LiPF}_{6}$ in nonaqueous tetraethylene glycol dimethyl ether (TEGDME), the N-GNS exhibited significantly improved electrocatalytic activity relative to undoped GNS evidenced by both fundamental rotating disk electrode and battery discharging tests [124]. These comparisons indicate that doped nitrogen sites yield more active sites (defects and functional groups) for $\mathrm{O}_{2}$ adsorption, and they provide more nucleation sites for the formation of discharging $\mathrm{Li}_{2} \mathrm{O}_{2}$ products with a more uniform dispersion. Similar promotional roles with nitrogen doping for $\mathrm{Li}-\mathrm{O}_{2}$ battery cathodes were also observed with vertically aligned nitrogen doped carbon nanotube arrays [125] and nitrogen-rich mesoporous carbon materials [126].

\section{M-N-C Carbon Composite ORR Catalysts}

\subsection{Synthetic Procedure}

While catalysts with good ORR activity in alkaline media can be prepared without any detectable metal content $[14,23]$, the presence of Fe and/or Co has been found so far to generate catalysts 
with the highest activity and four-electron selectivity in acidic environment $[11,13,40]$. The catalyst synthesis requires a careful and creative choice of precursors and templates along with controlled synthetic chemistry [40].

A great number of studies have demonstrated that the performance of the catalyst is directly related to the choice of precursors, carbon supports and synthetic steps. Although it may be true that there are a vast number of nitrogen precursors suitable for the catalysis of ORR, catalytic activity is greatly dependent upon the structure of these precursors. For instance, there are quite a few choices of nitrogen precursor including metal- $\mathrm{N}_{4}$ macrocycles (porphyrin complexes: $\mathrm{N}_{4}-\mathrm{Fe}$ and $\mathrm{N}_{4}$-Co) [127], small organic molecules such as pyrrole, acetonitrile and 1-methylimidazole, nitrogen-containing polymers involving polyaniline (PANI), melamine resin and poly-dopamine, and last but not least, inorganic nitrogen precursors such as sodium azide and ammonia gas [128]. Therefore, in order to synthesize an effective carbon based catalyst of the form M-N-C, a holistic approach may represent a more favorable strategy to address the activity and stability issues. Nitrogen-containing polymers are among the most promising and typically chosen precursors due to the fact that they exhibit a highly ordered structure which acts as a more stable carbon support active layer during pyrolysis [128].

In general, the synthetic procedure associated with the production of M-N-C catalysts initiates with a solution mixture containing transition metal, nitrogen-carbon precursors, and supports. After removing solvents, the resulting solid power is subject to a heat treatment at a temperature ranging from 700 to $1000^{\circ} \mathrm{C}$ (first heat-treatment). The first heat-treatment is followed by performing acid leaching, which readily eliminates undesired functional groups as well as unstable species from the pores of the catalysts. Thus, the porous morphology with more exposure active sites lead to an enhancement of ORR activity (Figure 8a) [37]. However, the 
acid washing step occasionally blocks active sites with oxygen containing functional groups introduced by the choice of acid $\left(\mathrm{H}_{2} \mathrm{SO}_{4}\right.$ or $\left.\mathrm{HNO}_{3}\right)$. Consequently, a second-heat treatment is required to further improve ORR activity by eliminating the damage caused by acid leaching (Figure 8a) [37].

Because the active sites are believed to be formed in the pyrolysis step, the activity of these sites would be greatly dependent on heating temperature in catalyst synthesis. As shown in Figure 8b, the ORR activities of PANI-Fe-C catalyst were studied as a function of heating temperature ranging from 400 to $1000^{\circ} \mathrm{C}$. The poor activity at $400^{\circ} \mathrm{C}$ is very similar to carbon materials, which means no new active site are formed until the temperature is higher than $600{ }^{\circ} \mathrm{C}$ showing a significant shift of ORR onset potential in the positive direction. Moreover, in terms of the most positive onset and half-wave potentials, $900{ }^{\circ} \mathrm{C}$ was found to be the optimized temperature to generate the most active catalyst for oxygen reduction.
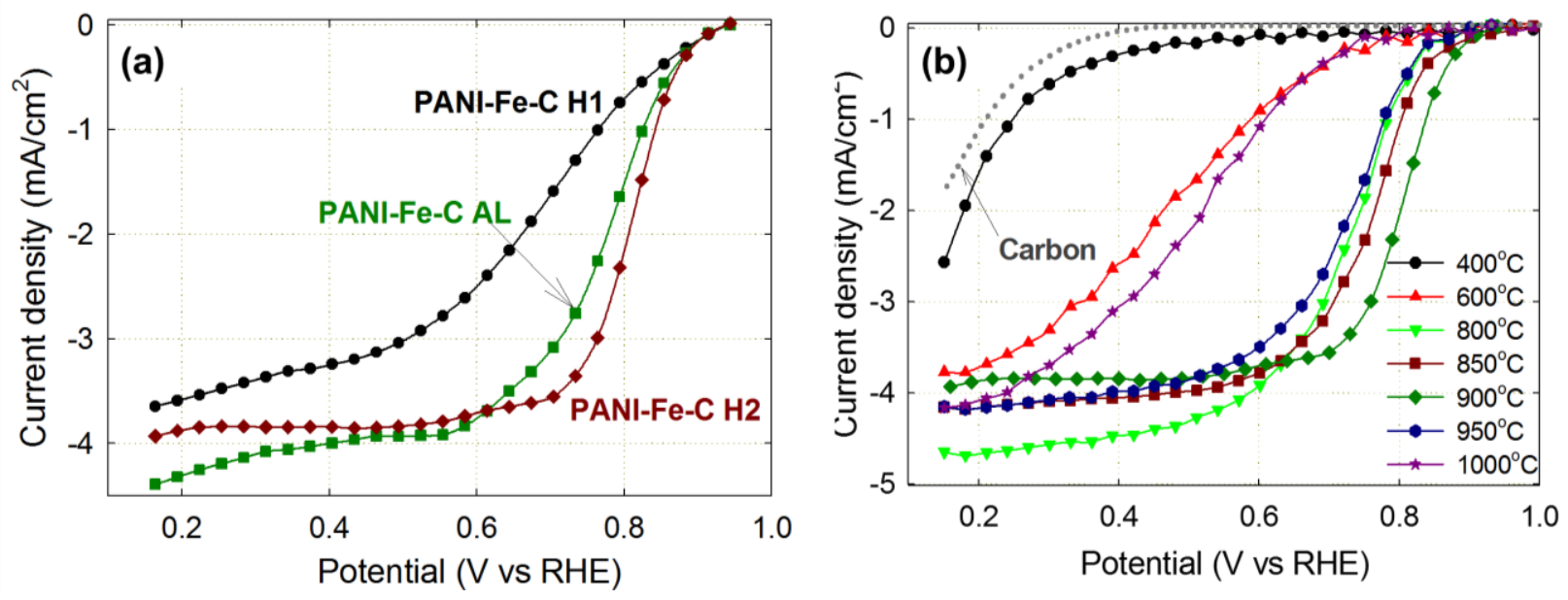

Figure 8. Effect of synthetic procedure (a) and heating temperatures (b) on the oxygen reduction activity of PANI-derived Fe-N-C catalysts. Reproduced with permission from Ref [37]. Copyright 2011, Royal Society of Chemistry.

Elemental quantification of these samples treated at different temperatures were as determined using X-ray photoelectron spectroscopy (XPS). It was found that Fe content increases with pyrolysis temperature; this was probably due to more Fe species being 
incorporated into the graphitized carbon structure at higher temperatures suggested by as HRTEM imaging [11]. Carbon content also increased with heating temperature as carbonization of PANI, leading to the formation of graphitic carbon on surface layer resulting from carbonization of PANI. In addition, nitrogen content decreases with heating temperatures from 600 to $900{ }^{\circ} \mathrm{C}$, but it does not lead to a drop of ORR activity in this temperature range. Therefore, it appears the activity is not solely dependent on the total amount of doped nitrogen as others have claimed, but probably more related to the doping position and local electron environments
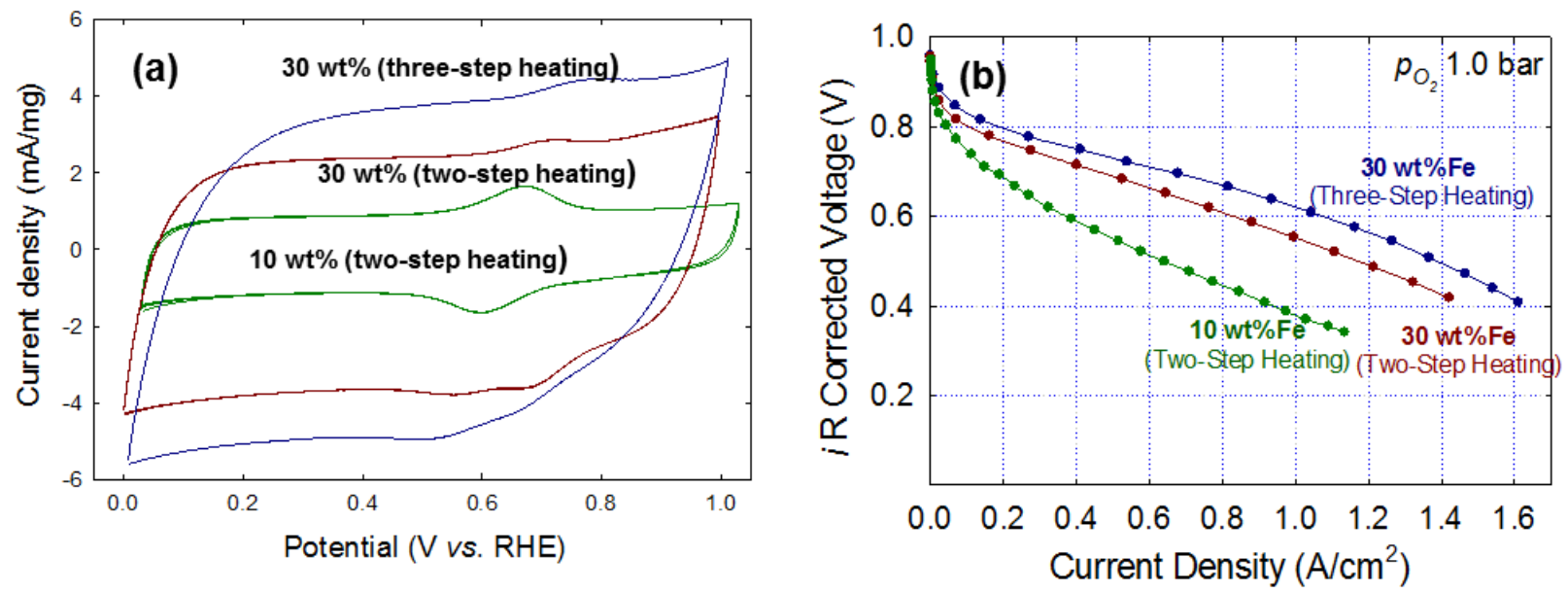

Figure 9. (a) Cyclic voltammetry (Reproduced with permission from Ref [31], Copyright 2014, American Chemical Society) and (b) fuel cell performance for various PANI-Fe-C non-PGM catalyst. Cyclic voltammetry condition, $20 \mathrm{mV} / \mathrm{s}$ in $0.5 \mathrm{MH} 2 \mathrm{SO} 4$ solution. Fuel cell tests: Anode: $0.5 \mathrm{mg} / \mathrm{cm}^{2} \mathrm{Pt}$ (E-TEK) 1.0 bar (partial pressure), $\mathrm{H}_{2} 200 \mathrm{sccm}$; Cathode: $4.0 \mathrm{mg} / \mathrm{cm}^{2} 1.0$ bar (partial pressure), $\mathrm{O}_{2} 200$ sccm; Membrane: Nafion ${ }^{\circledR} 211$; Cell: $80^{\circ} \mathrm{C} ; 100 \%$ RH.

Beside the heating temperature, heating steps are found to be very important to catalytic activity. Recently, Los Alamos scientists developed a novel three-step heating strategy to prepare high-surface-area Fe-N-C catalysts. The new cathode catalysts exhibit increased electrochemically accessible surface areas, relative to traditional two-step synthesis (Figure 9a) 
[31]. Importantly, it can generate a current density of $190 \mathrm{~mA} \mathrm{~cm}^{-2}$ at a voltage of $0.80 \mathrm{~V}$ (iRfree) in fuel cell testing (Figure 9b) [129].

\subsection{Role of Transition Metals in Carbon Catalysts}

These promising transition metal-containing organometallic complexes have been meticulously investigated since their discovery back in 1964 [130], however, it was fairly recent that major progress towards their improvement took place. Usually, nanostructured carbon (e.g., tubes, onion-like carbon, and multiple-layered graphene) were observed in highly active M-N-C catalysts (Figure 10) $[41,43,76,77]$. A more specific hypothesis to explain the role of carbon structures in catalysis is that the carbon derived from the graphitization process of nitrogencarbon precursors (e.g., polyaniline, ethylenediamine, melamine, or cyanamide) in the presence of transition metals (Fe, Co or $\mathrm{Ni}$ ), may serve as a matrix for hosting active nitrogen or metal moieties $[11,76]$. The nanostructures of highly graphitized carbon are greatly dependent on the employed transition metals and nitrogen-carbon precursors (Figure 10) [41,77,131], which directly correlate to catalytic activity. 

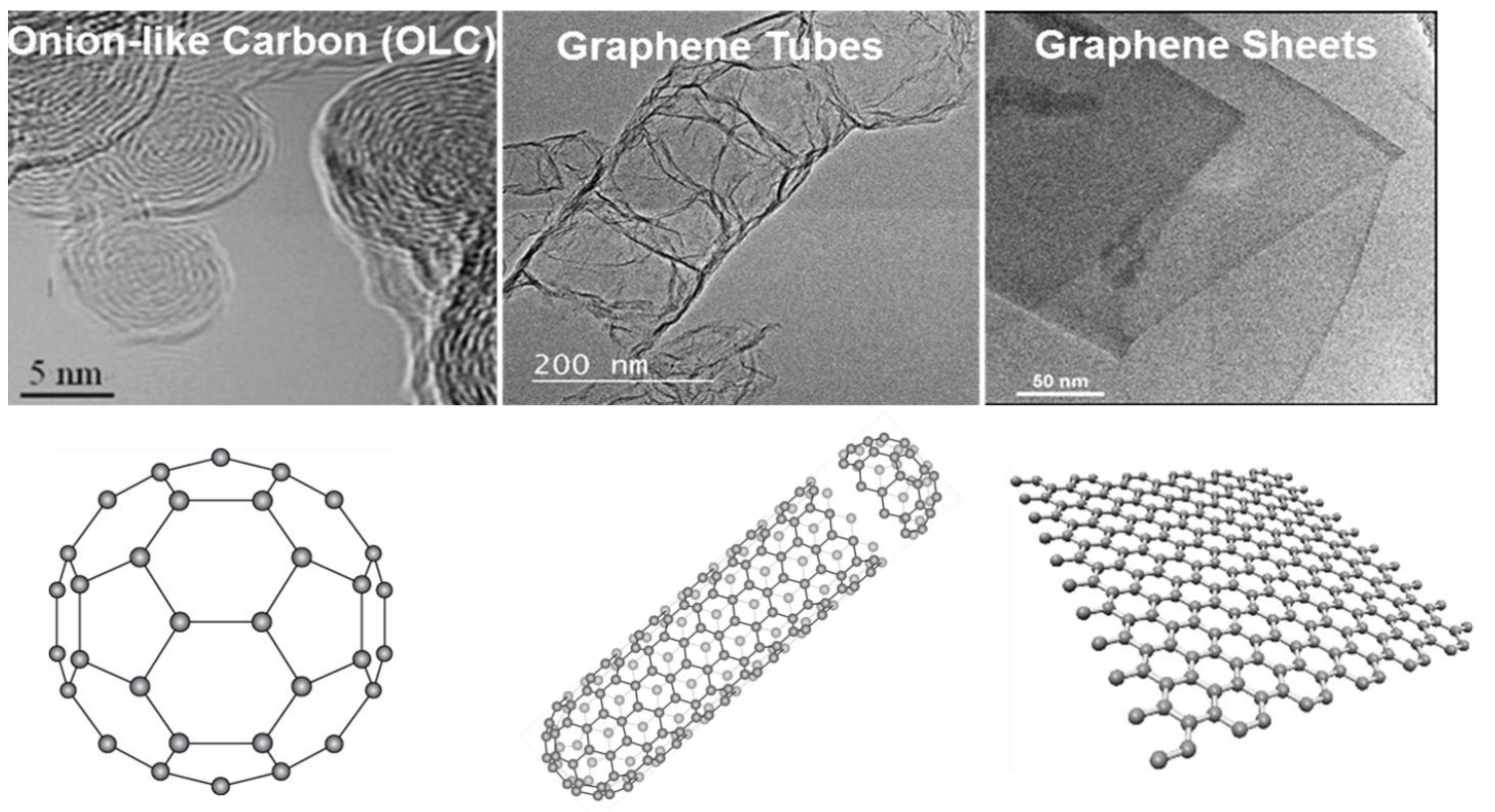

Figure 10. Diversified carbon nanostructures observed in various $\mathrm{M}-\mathrm{N}-\mathrm{C}$ catalysts synthesized from a high-temperature graphitization. Reproduced with permission from Ref [41,77,131]. Copyright 2011, Elsevier; Copyright 2014 Wiley-VCH; Copyright 2012, American Chemical Society, respectively.

Furthermore, there is a possibility that a transition metal (e.g., Fe, up to 5 at $\%)$ cation is able to coordinate with pyridinic nitrogen and embed itself into the carbon plane as a possible active site configuration [40], which provides enhanced intrinsic ORR activity compared to the metalfree $\mathrm{N}$-doped carbon. However, it is unclear whether the transition metals are the crucial center of the active site(s), or only catalyze the process of nitrogen doping into carbon. In this part, we aim to discuss some of the most relevant findings and potential effects of the addition of transition metals on the structure and performance of the carbon catalyst.

Compared to other transition metals, $\mathrm{Co}$ and $\mathrm{Fe}$ are the most efficient enhancers of catalyst activity in the ORR. The performance of these transition metals was found to be dependent on the type of electrolytes utilized. As shown in Figure 11, in the case of PANI-derived catalysts $[37,38,41]$, the Fe-N-C catalyst exhibits much higher activity in acidic electrolyte, relative to the 
Co-N-C catalyst. However, in alkaline and nonaqueous $\mathrm{Li}^{+}$electrolytes, the Co-N-C catalyst is greatly superior to the Fe-N-C catalyst [37,41]. These results suggest that the optimal active site structures for the ORR in various media are likely different. It will be very important to fundamentally understand the active sites and associated reaction mechanisms for each electrolyte behind these interesting experimental observations.
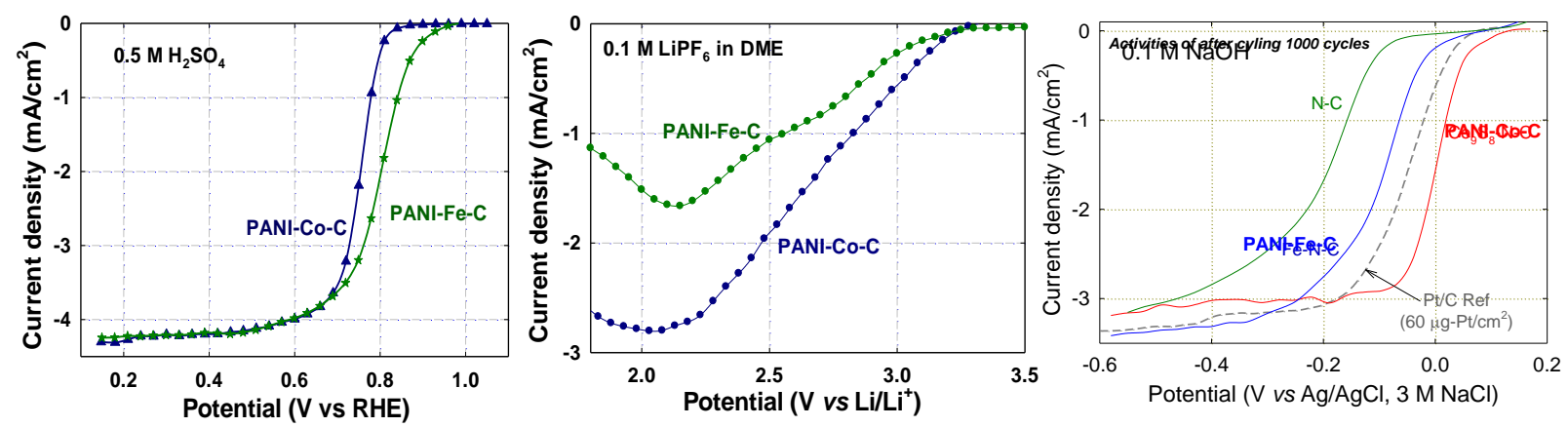

Figure 11. Catalytic activity of polyaniline (PANI)-derived $\mathrm{M}-\mathrm{N}-\mathrm{C}$ catalysts for the ORR in 0.5 $\mathrm{M} \mathrm{H}_{2} \mathrm{SO}_{4}, 0.1 \mathrm{M} \mathrm{LiPF}_{6}$ in DME, and 0.1 M NaOH electrolytes. Reproduced with permission from Ref [37]. Copyright 2011, Royal Society of Chemistry; Reproduced with permission from Ref [41], Copyright 2012, American Chemical Society; Produced with permission from Ref. [132], Copyright 2009, the Electrochemical Society.

In order to gain more insight about the role of Co and Fe in catalyst synthesis, especially during the graphitization of PANI, nanostructure and morphology of Fe-N-C and Co-N-C catalysts were compared using electron microscopy (Figure 12) [37]. Interestingly, graphenesheet structures abundantly exist in Co-N-C catalysts, but not in Fe-N-C catalyst. This significant difference in catalyst nanostructure implies that Co is likely more effective to catalyze PANI decomposition at the atomic level, then these carbon and nitrogen atoms will re-arrange and coalesce together, forming highly graphitic N-doped graphene structures. Since the nitrogen functional structure on such non-precious catalyst are believed to be important to active sites, the correlation between transition metals and resulting nitrogen doping would provide insight into 
the origin of active sites. As shown in Figure 12 [37], the addition of Co leads to a relatively higher pyridinic nitrogen content and is able to catalyze nitrogen doping at the edge of graphene planes [37]. Conversely, Fe may play a promotional role in increasing graphitic nitrogen and catalyze nitrogen doping at the center of graphene [37].
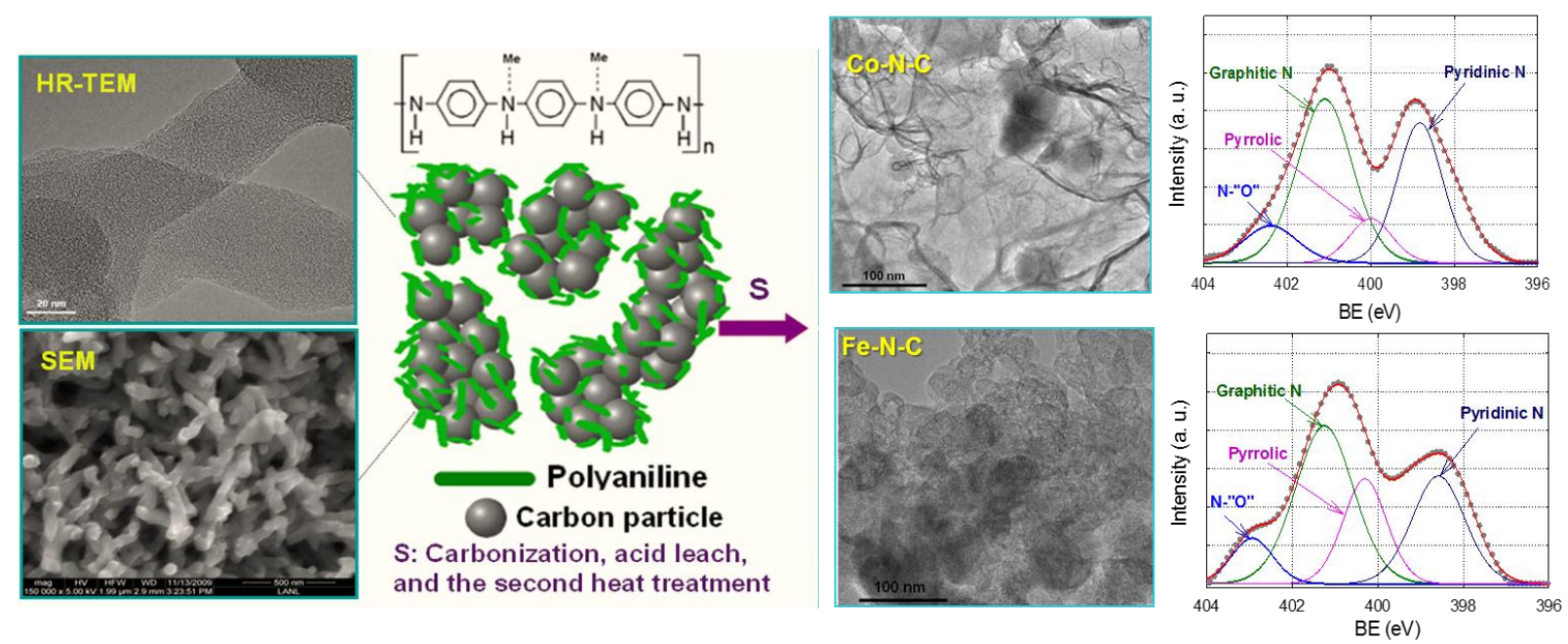

Figure 12. Morphology and nitrogen doping of $\mathrm{Co}-\mathrm{N}-\mathrm{C}$ and $\mathrm{Fe}-\mathrm{N}-\mathrm{C}$ catalysts derived from PANI. Reproduced with permission from Ref. [37]. Copyright 2011, Royal Society of Chemistry.

In addition, bonding structural information for these transition metals in catalyst can be determined by using ex-situ X-ray absorption. In the Co-N-C catalyst case, similar to standard cobalt metal (hcp), the dominant peak in the catalyst is around $2 \AA$ belonging to the Co-Co shell. This result indicates that the principal Co species in catalyst is highly metallic and no significant Co-N coordination was found. Similar results were also observed in another Co-N-C catalyst derived from ethylenedimine, a different nitrogen-carbon precursor. When pyrolysis temperature was above $800^{\circ} \mathrm{C}$, the Co-N bonds were totally broken and metallic Co-Co bond newly formed. In the case of $\mathrm{Fe}-\mathrm{N}-\mathrm{C}$ catalysts, the spectroscopy shows a dominant peak around $1.63 \AA$, which is very close to typical $\mathrm{Fe}-\mathrm{N}_{4}$ structures in macrocyclic compounds, suggesting that the $\mathrm{Fe}-\mathrm{N}$ coordination structure is very possible in the PANI-derived Fe-N-C catalyst [37]. It was reported 
that high-resolution $\mathrm{N}$ 1s XPS could discriminate nitrogen coordinated to iron $(\mathrm{N}-\mathrm{Fe})$ with a binding energy at $399.6 \mathrm{eV}$ from other doped nitrogen structures [133]. However, with the peak very close to pyrrolic nitrogen $(400.5 \pm 0.3 \mathrm{eV})$, it is impossible to clearly identify the Fe-N coordination [87]. Furthermore, Mössbauer spectra indicated that various Fe-N coordination formulations in the same Fe-N-C catalyst were very likely, which included slow-spin $\mathrm{Fe}^{2+} \mathrm{N}_{4}$ centers, a 3-fold coordinated high spin $\mathrm{CFe}^{2+} \mathrm{N}_{2},\left[\mathrm{FeN}_{4}\right]^{2-}$ (doublet D2), a ferrous high-spin $\mathrm{Fe}-$ $\mathrm{N}_{4}$ center, and a nonstoichiometric $\mathrm{Fe}_{x} \mathrm{~N}$ [133]. In addition, Koslowski et al. [134], once used ${ }^{57} \mathrm{Fe}$ Mössbauer spectra to study a heat-treated iron porphyrin (FeTMPPCl) model catalyst. All of catalyst spectra can be fitted assuming two different ferrous $\mathrm{Fe}-\mathrm{N}_{4}$ centers, a $\mathrm{CFeN}_{2}$ center $\left(\mathrm{Fe}^{2+}\right.$, $S=2)$ and a $\mathrm{Fe}_{3} \mathrm{C}$ center $\left(\mathrm{Fe}^{0}\right)$. A linear correlation was found between the kinetic current density related to the direct oxygen reduction and the amount of in-plane $\mathrm{Fe}-\mathrm{N}_{4}$ centers. It should be noted that, although these characterization techniques are not surface sensitive, they can still provide insightful origin into the possible active iron structures in these highly-active catalysts. Therefore, due to the absence of Co-N coordination structures in Co-N-C catalysts, metal-free pyridinic or/and graphitic $\mathrm{N}$ dominant in catalysts seems to be important to ORR activity, particularly in alkaline and nonaqueous electrolytes. In the acidic electrolyte, as evidenced by Xray absorption and Mössbauer spectroscopy results, Fe-N coordination structures may directly involve into the active ORR sites with higher intrinsic activity than that of the corresponding "metal-free" nitrogen-doped carbon structures $\left(\mathrm{CN}_{\mathrm{x}}\right)$.

Nanocarbon morphology of M-N-C catalysts can be greatly tuned by the metals that are used for synthesis. Recently, we demonstrated a new strategy for tuning the size of large-diameter and few-walled nitrogen-doped carbon nanotubes (N-CNTs) from 50 to $150 \mathrm{~nm}$ by varying the 
transition metal $(\mathrm{TM}=\mathrm{Fe}, \mathrm{Co}, \mathrm{Ni}$ or $\mathrm{Mn})$ used to catalyze graphitization of dicyandiamide

(Figure 13) [135].

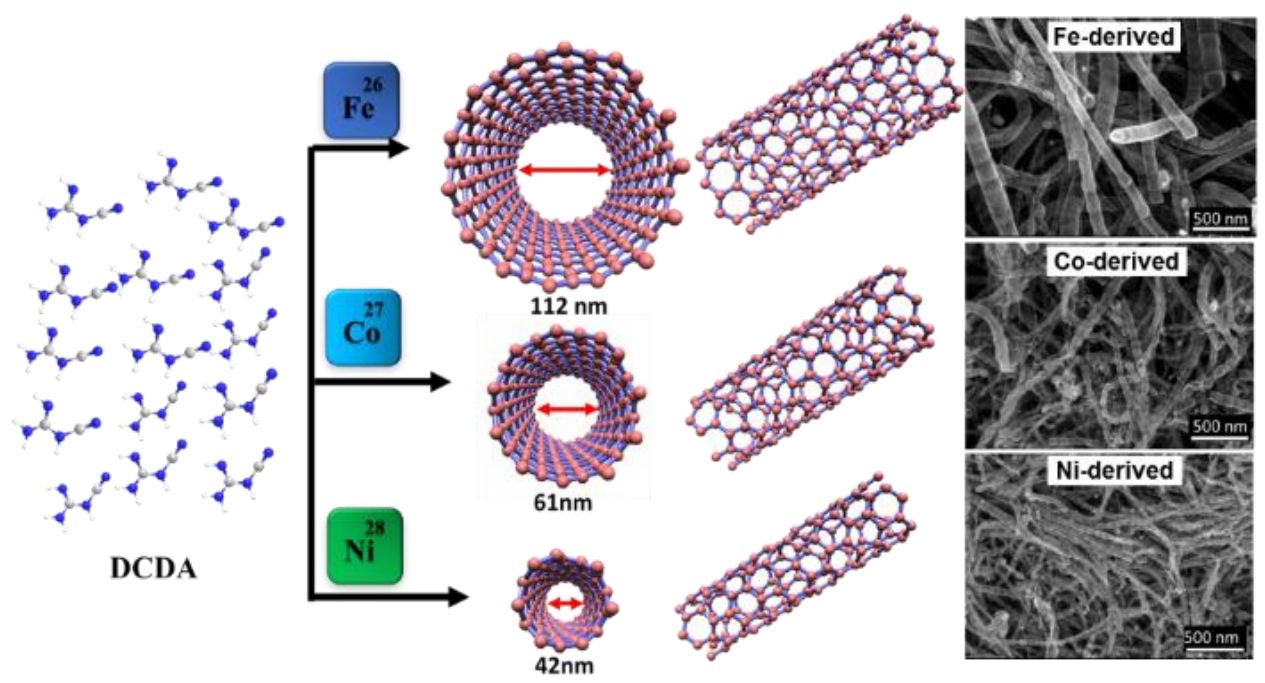

Figure 13. An approach to preparing large-size carbon nanotubes with tunable diameter by using different metal precursors. The average diameter of Fe-, Co-, and Ni-derived tubes are 112, 61, $42 \mathrm{~nm}$, respectively. Reproduced with permission from Ref. [135]. Copyright 2015, Royal Society of Chemistry.

Notable, compared to extensively studied cyanamide, dicyandiamide is much cheaper and contain more nitrogen atoms. In this work, Fe yielded the largest tubes, followed by Co and Ni, while Mn produced a clot-like carbon morphology. The corresponding morphology is correlated with electrocatalytic activity for the oxygen reduction. A clear trend of $\mathrm{Fe}>\mathrm{Co}>\mathrm{Ni}>\mathrm{Mn}$ was observed for ORR catalytic activity in both alkaline media and more demanding acidic media. The Fe-derived N-CNTs exhibited the highest BET $\left(\sim 870 \mathrm{~m}^{2} / \mathrm{g}\right)$ and electrochemically accessible $\left(\sim 450 \mathrm{~m}^{2} / \mathrm{g}\right)$ surface areas and, more importantly, the highest concentration of nitrogen incorporated into the carbon planes. Thus, in addition to the intrinsic high activity of Fe-derived catalysts, the appropriate morphology features including high surface area and nitrogen doping contribute to ORR activity enhancement. This suggest that generation of favorable morphology 
can further provide a new opportunity to prepare advanced $\mathrm{Fe}-\mathrm{N}-\mathrm{C}$ catalysts with improved activity and durability.

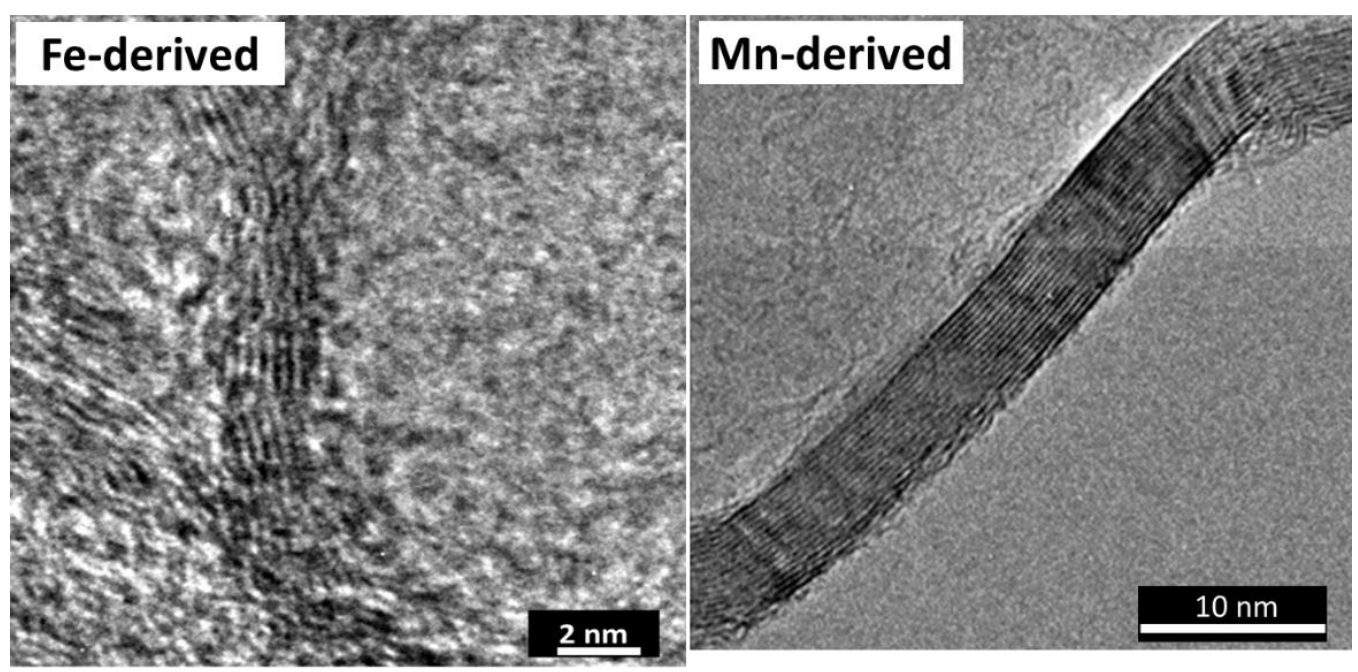

Figure 14. HR-TEM images revealing the subtle structures of carbon nanotubes and nanoshells derived from Fe and Mn. Reproduced with permission from Ref. [135]. Copyright 2015, Royal Society of Chemistry.

In addition, substantial defects such as vacancies and dislocations observed in carbon planes may be responsible for the high ORR activity. As shown in Figure 14, Fe-derived carbon tubes contain a large amount of defects. On the other hand, the well-defined and highly ordered carbon layer structures were produced in the presence of $\mathrm{Mn}$. These microscopy image results suggest that lack of defects in the ordered carbon structures can be a disadvantage for electrocatalysis and may significantly limit the electrocatalytic activity. Apart from the types of transition metals, we also found, in some special cases, metal content used for synthesis plays an important role in morphology optimization and activity enhancement. For example, when aniline was in-situ polymerized by sulfur-containing APS oxidant and used for a nitrogen-carbon precursor, a nominal iron loading of $\mathrm{FeCl}_{3}$ can be used to control surface area, porosity, and morphology. 

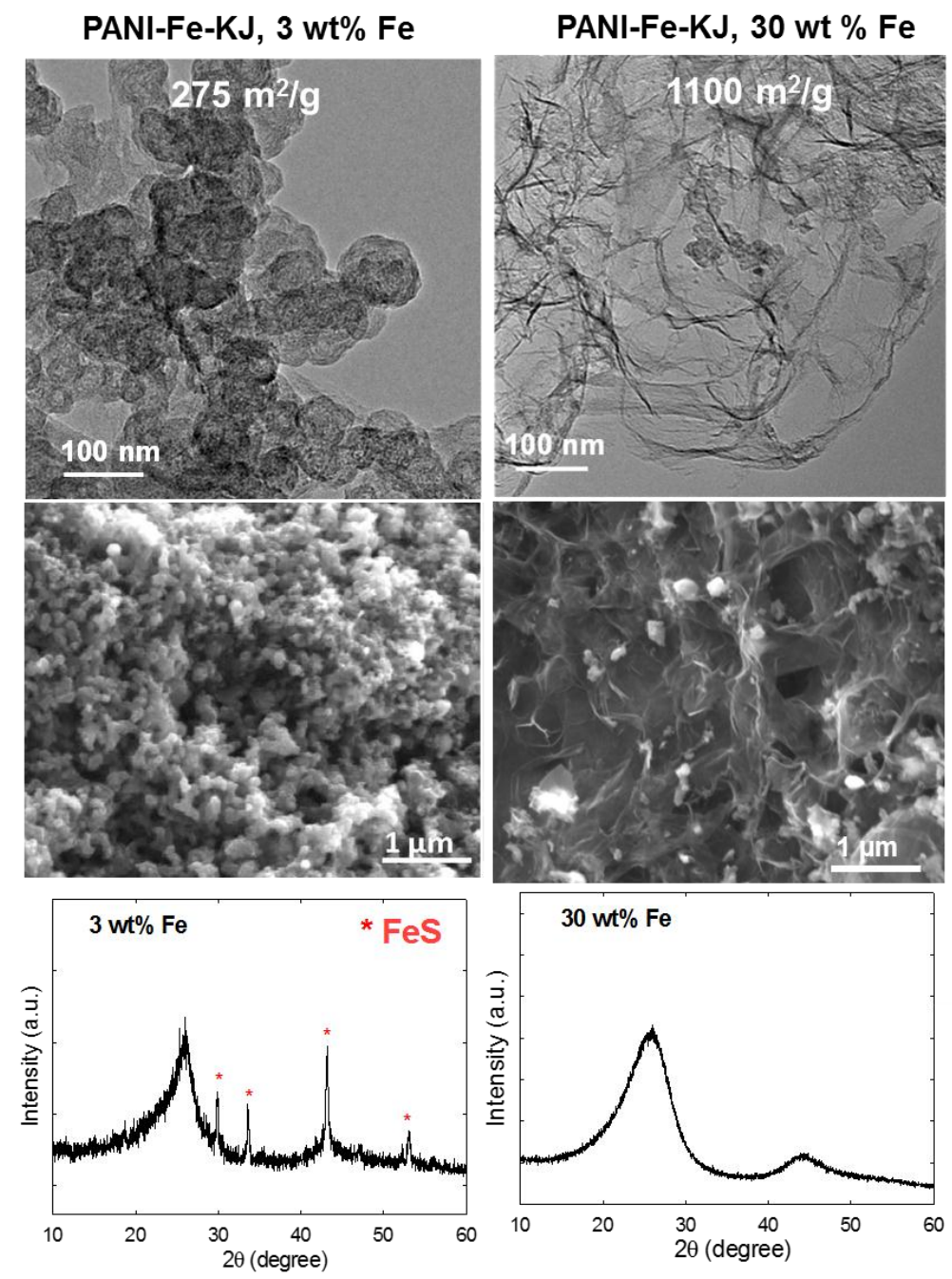

Figure 15. Microscopy images and XRD patterns of Fe-N-C catalysts as function of the amount of nominal metal used for synthesis. Reproduced with permission from Ref [31], Copyright 2014, American Chemical Society.

For example, 30wt\% Fe-derived final catalyst (after acidic leaching and second heating treatment) has a 3D highly porous structure with an exceptionally increased surface area of 1100 $\mathrm{m}^{2} \mathrm{~g}^{-1}$, when compared with traditional $3 \mathrm{wt} \% \mathrm{Fe}\left(275 \mathrm{~m}^{2} / \mathrm{g}\right)$ used during the synthesis. Only 2 wt $\%$ Fe was detected in the 30wt\% Fe catalyst using XPS and ICP-MS after acid washing and a second heat treatment. In good agreement with BET results, the morphology of the catalysts 
observed by SEM in Figure 15 [31] show more porosity when higher nominal iron loadings were used. In addition, contrary to the $3 \mathrm{wt} \%$ Fe-derived catalysts containing detectable FeS crystalline, the $30 \mathrm{wt} \% \mathrm{Fe}$-derived catalyst only contained carbon peaks and lacked FeS peaks in the XRD pattern (Figure 15) [31]. Thus, in contrast to the 3 wt \% Fe-derived catalysts, in situ formed $\mathrm{FeS}$ in the 30 wt \% Fe-derived catalyst is more efficiently leached out during the acid treatment step. The fact that the highest initial Fe loading used in the synthesis leads to the lowest bulk Fe content in the final product as well as the highest BET surface area may indicate that the in situ formed FeS acts as an effective sacrificial pore-forming agent during acid leaching. It is possible that the FeS particles formed with lower Fe loadings of 3 wt $\%$ are more fully encapsulated within carbon agglomerates.

Notable, rumpled multilayered graphene sheet-like morphology was observed with the highsurface-area 30wt\% Fe-derived catalysts. An ADF-STEM image of a multilayered graphene sheet and associated EELS analysis indicates that single Fe atoms are dispersed across the surface of the graphene. These $\mathrm{Fe}$ atoms were highly mobile under the electron beam, indicating that $\mathrm{Fe}$ is not incorporated within the carbon lattice. Additionally, EELS identified nitrogen in thicker areas of the layered graphene sheets. Beside the high ORR activity in traditional $0.5 \mathrm{M}$ $\mathrm{H}_{2} \mathrm{SO}_{4}$ solution, the high-surface-area Fe-based catalysts (PANI-Fe-C) can tolerate phosphate ions at high concentrations and deliver ORR performance in $5.0 \mathrm{M} \mathrm{H}_{3} \mathrm{PO}_{4}$ that is superior to that of Pt/C catalysts (Figure 16) [31]. 

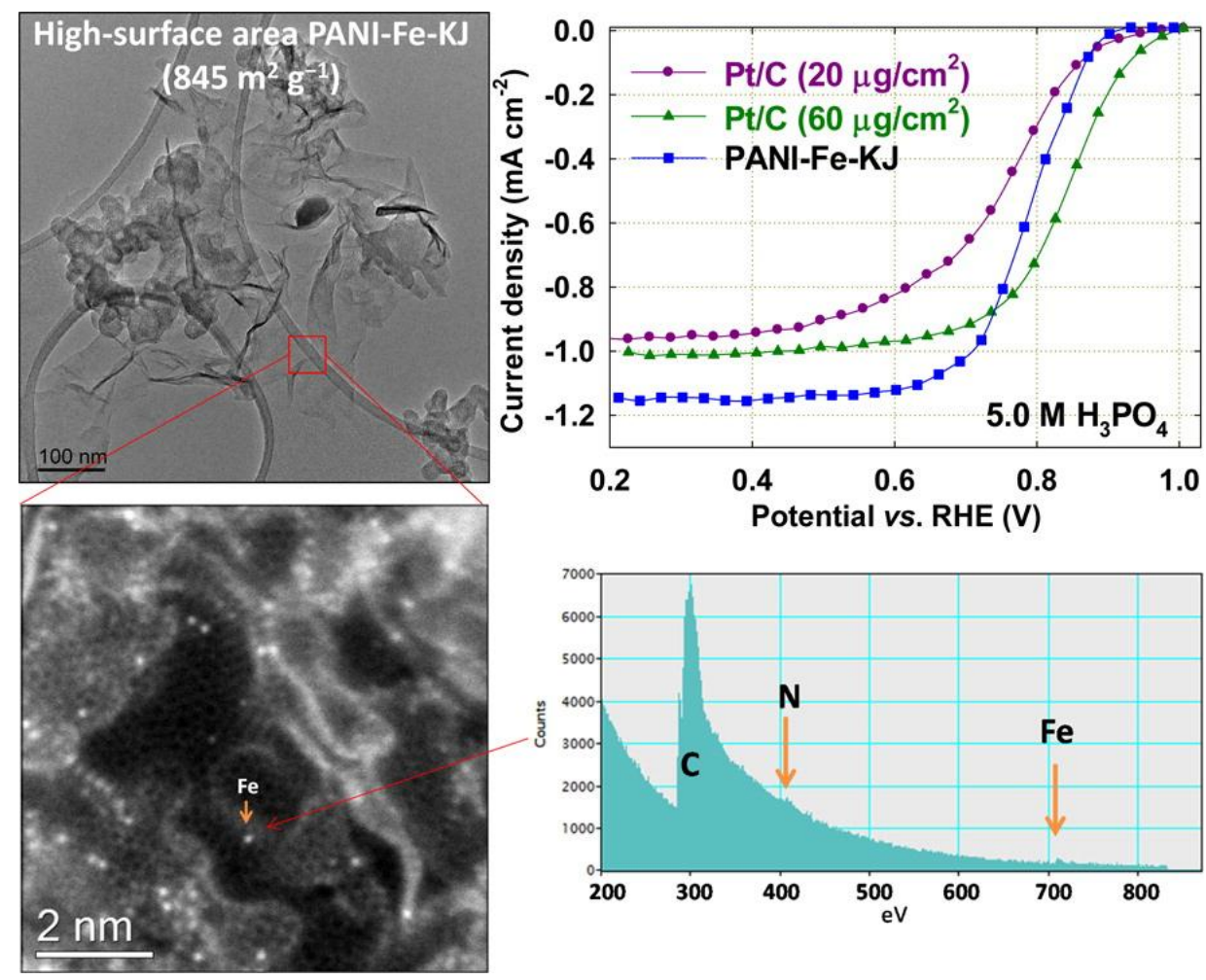

Figure 16. Morphology and elemental composition of PANI-derived Fe-N-C catalyst and its ORR activity in 5.0 $\mathrm{M} \mathrm{H}_{3} \mathrm{PO}_{4}$. Reproduced with permission from Ref. [31], Copyright 2014, American Chemical Society.

\subsection{Role of Carbon Supports}

During the synthesis of Fe/Co-N-C catalysts, the addition of carbon supports is usually required to serve as a template that will disperse or adsorb the nitrogen-carbon and transition-metal precursors. In doing so, the subsequent heat-treatment yielded uniform distribution of active sites associated with nitrogen and transition metal moieties. However, the impact of supports was found to be different for Co- and Fe-based catalysts. 
(a)
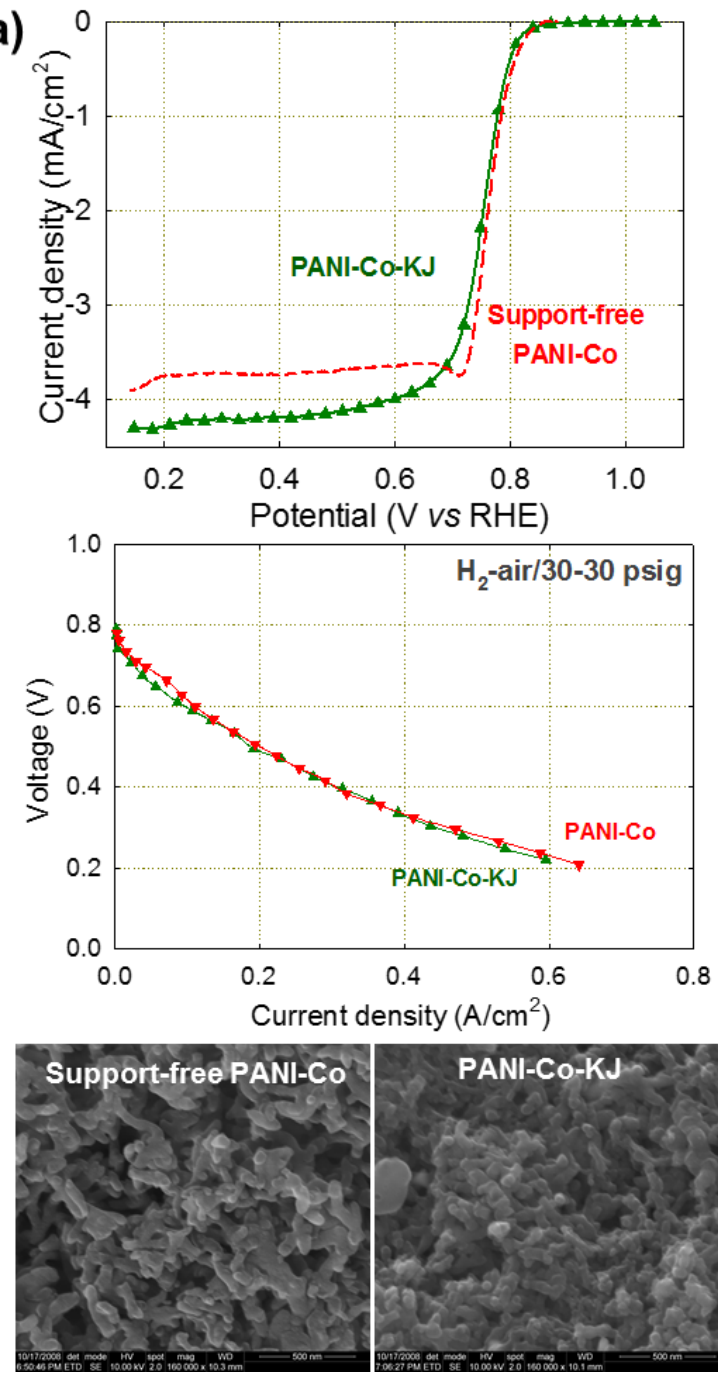

(b)
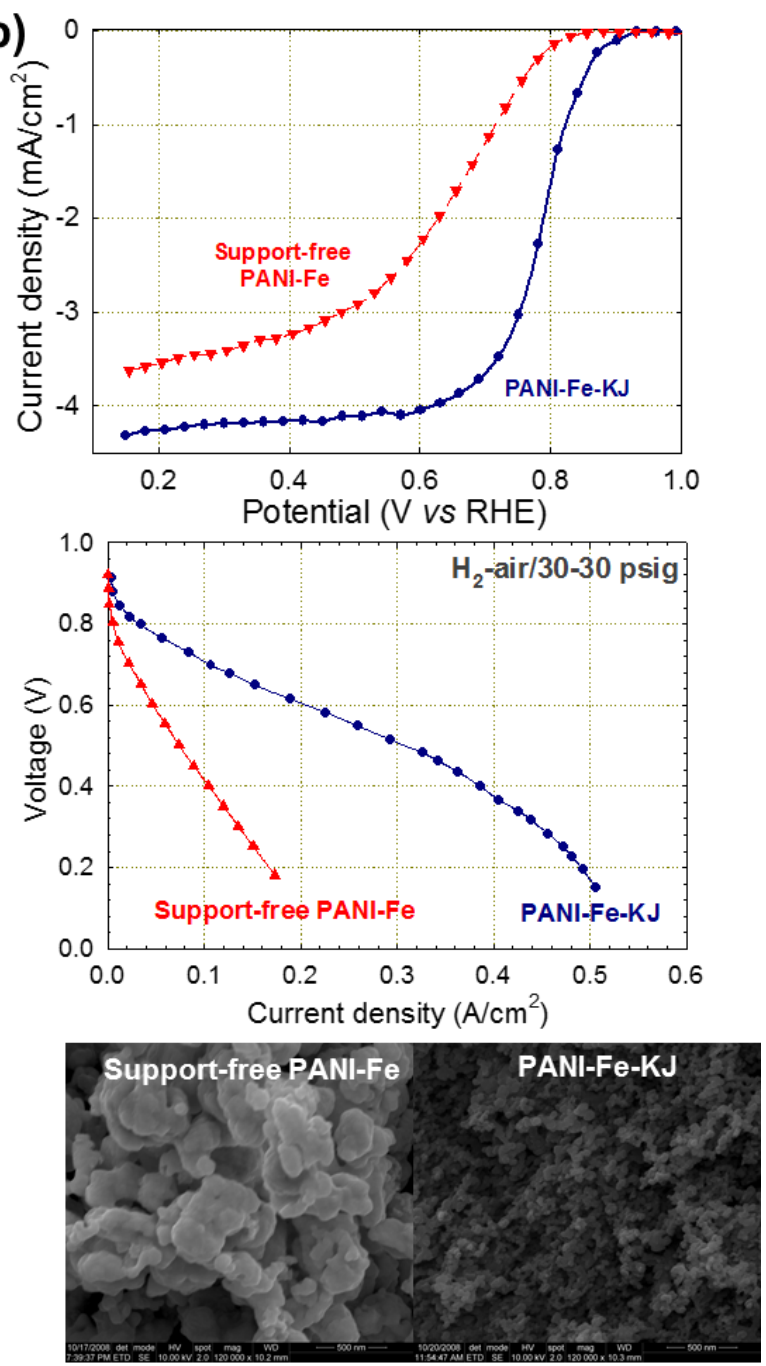

Figure 17. Effect of carbon supports on Co-N-C and Fe-N-C catalysts in terms of their ORR activity, fuel cell performance, and morphologies.

As shown in Figure 17, when PANI was used as a carbon-nitrogen precursor, morphology and ORR activity of the Co-N-C catalyst are nearly the same regardless of support usage. Oppositely, ORR activity and the associated catalyst morphology of $\mathrm{Fe}-\mathrm{N}-\mathrm{C}$ are more greatly dependent on the use of supports. The high-surface area ketjenblack lead to more uniform and porous morphology for the $\mathrm{Fe}-\mathrm{N}-\mathrm{C}$ catalyst, exhibiting markedly enhanced activity for the ORR as evidenced by both RDE and fuel cell tests. This significant dissimilarity suggested that the 
formation mechanism of active sites during the high-temperature treatment for $\mathrm{Co}$ - and $\mathrm{Fe}$ derived catalysts are likely different. Co species may have stronger catalytic function to catalyze a complete graphitization of nitrogen-carbon precursors (e.g., PANI) and spontaneously create sufficient porosity. However, significant agglomeration of nitrogen-carbon precursors during the high-temperature treatment is very likely in the presence of Fe species, yielding less porous morphology. In addition, close integration of $\mathrm{Fe}$ and $\mathrm{N}$ species adsorbed into porous supports appears imperative for subsequent thermal treatment and the generation of active sites related to $\mathrm{FeN}_{\mathrm{x}}$ moieties. The similar role of carbon supports was also observed with other nitrogen-carbon precursors-derived catalysts including ethylenediamine, melamine, and cynamide. However, the situation might differ if different precursors such as metal organic frameworks (MOFs) are used for synthesis of M-N-C catalysts [136].

In addition to the morphology control and activity enhancement, utilization of advanced nanocarbon supports was also found to be capable of improving performance durability of catalysts. Due to their high electronic conductivity, good corrosion resistance, high specificsurface area, and diminishing price, carbon nanotubes have been considered a possible replacement of traditional carbon blacks in fuel cell electrocatalysts. A number of earlier studies have shown that Pt, loaded on multi- and single-walled carbon nanotubes, exhibits high activity for methanol electro-oxidation and oxygen reduction. We have systematically compared Ketjenblack 300J and multiwalled carbon nanotube (MWNTs) supports in terms of their capability to enhance catalyst performance. 

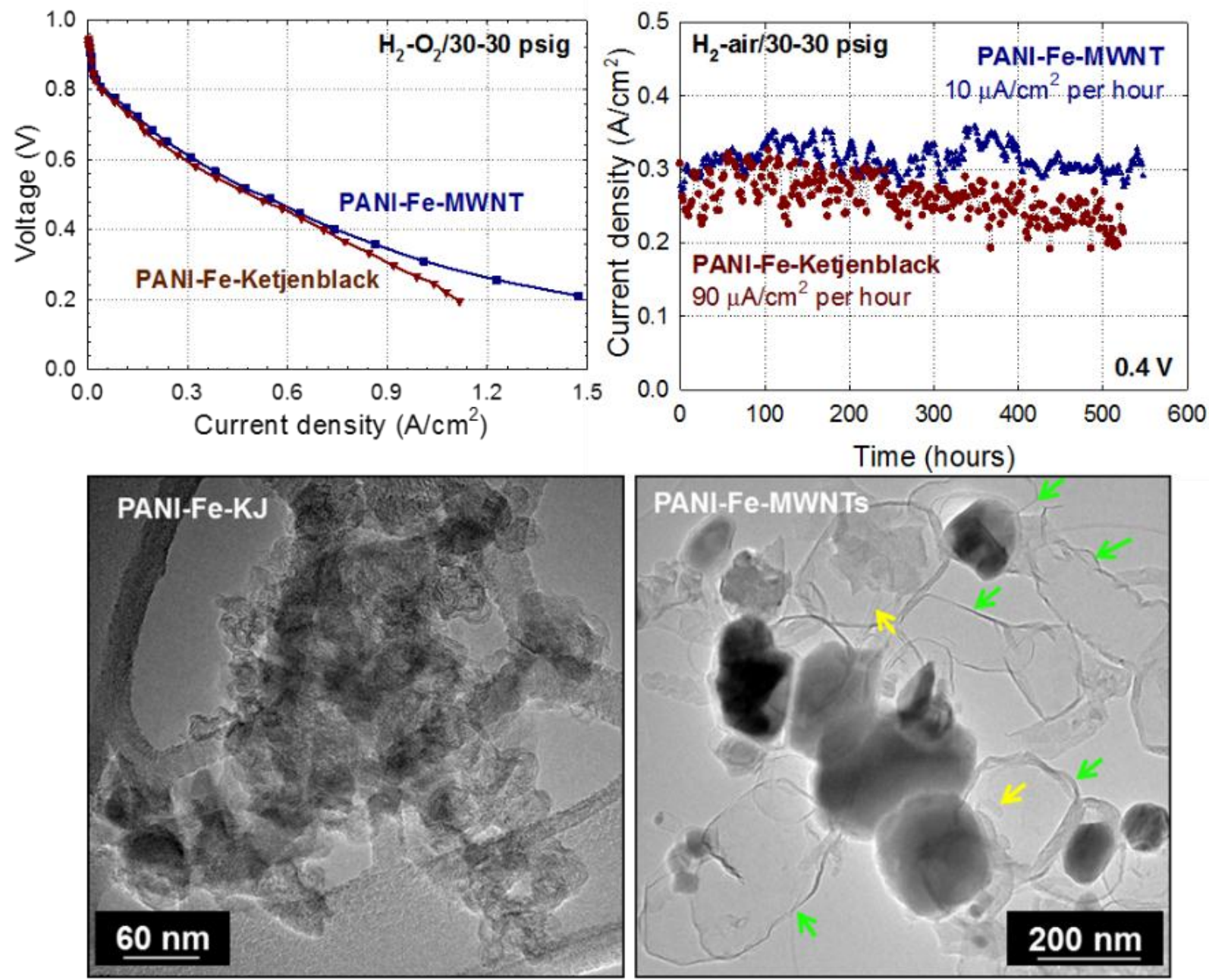

Figure 18. Fuel cell performance of PANI-derived Fe-N-C catalyst obtained using MWNTs and Ketjen black as supports: (a) initial fuel cell polarization plots, (b) life tests, and (c) morphologies (graphene marked by green arrows; nanotube marked by yellow arrows). Reproduced with permission from Ref. [137]. Copyright 2011, Royal Society of Chemistry.

As shown in Figure 18 [137], initial fuel cell performance evaluation (i.e., polarization plots) measured with PANI-Fe-KJ and PANI-Fe-MWNTs is nearly identical. However, the MWNTsupported catalyst generated a higher current density at relatively low voltage $(<0.35 \mathrm{~V})$. This is likely due to the higher electronic conductivity and more open electrode structure that result from MWNTs. More importantly, the MWNT supported catalyst demonstrates significant stability benefits, with virtually no performance degradation after more than 500 hours at a constant cell 
voltage of $0.40 \mathrm{~V}$. This represents an improvement over the Ketjen black-supported catalyst that exhibits performance loss at operating times exceeding 200 hours. Since the CNTs do not possess micro-porosity, except in the interior of the tube, higher gas permeability is expected, and the active catalytic sites on the nanotubes are likely to be easily accessible. In addition, water removal within the electrode should be facilitated, and this is an important advantage for CNTs, especially in the case of non-precious catalyst layers approaching $100 \mu \mathrm{m}$ in thickness. Higher durability of the MWNT-supported PANI-Fe catalyst may be related to the higher degree of graphitization of MWNTs, which leads to enhanced corrosion resistance and improved stability of the ORR active site(s) $[90,138]$.

\subsection{Novel M-N-C Catalysts Derived from MOFs}

Traditional synthesis approaches of M-N-C catalysts are to integrate different metal, nitrogen and carbon precursors in composites as templates followed by high temperature carbonization. For example, in the traditional synthesis of catalysts, nitrogen-carbon precursors such as polyaniline, melamine, and ethylenediamine usually coordinate with transition metal salts to form complexes deposited on carbon supports. They then pyrolyze at high temperature under inert gas atmosphere to generate excellent catalysts for the ORR [139]. However, these composites with complex structures fail to control precursors and create well-defined structure with ordered morphology and pore sizes. This lack of structure control during carbonization limits the rational design to enhance the performance of catalysts as well as the understanding of the active sites of catalysts for ORR.

MOFs, built by secondary building of units from metals and organic linkers with strong bonding, have received a lot of attentions since they possess permanent porosity, threedimensional (3D) structure and diversity of metals and organic linkers. They have promising 
applications in gas storage, separation and catalysis and especially in energy conversion and storage [140]. The structure of MOFs consists of ligands containing carbon and nitrogen atoms coordinating with metals to form ordered 3D porous crystals. These not only meet the requirements of $\mathrm{M}-\mathrm{N}-\mathrm{C}$ composition as templates but also provides ordered three dimensional porous structures. Additionally, the strong interaction among metal atoms and nitrogen atoms beneficial to generating more active sites and higher intrinsic catalytic active sites via carbonization. Liu and coworkers initiated the study of M-N-C catalysts derived from MOFs for ORR cathodes in fuel cells $[141,142]$. Following their pioneering works, the most active catalyst derived from MOF was prepared by Proietti et al.[143] through physical mixing of ZIF-8, a zeolitic imidazolate framework (ZIF) composed of $\mathrm{Zn}$ and 2-methylimidazole, with $\mathrm{N}$-chelating Fe compounds using ball milling followed by two annealing treatments using $\mathrm{Ar}$ and $\mathrm{NH}_{3}$, respectively. Single MEA fuel cell tests using $\mathrm{H}_{2}-\mathrm{O}_{2}$ indicated that the best performing cathode from that work [143] generated a power density of $0.75 \mathrm{~W} \mathrm{~cm}^{-2}$ at $0.6 \mathrm{~V}$, which is comparable with that of a commercial Pt-based cathode tested under identical conditions (Figure 19). Besides the intrinsically active Fe-N species in the catalysts, the utilization of the unique ZIF-8 MOF templates also significantly improved mass transport properties. Both SEM and TEM images clearly indicated that there are numerous mesopores of about $50 \mathrm{~nm}$ in diameter dominant throughout the catalyst; they contain interconnected hollower structures and have typical wall thicknesses of less than $10 \mathrm{~nm}$. Therefore, the high-surface-areas and porous structures greatly facilitate the diffusion of ORR-related species $\left(e . g\right.$., $\mathrm{O}_{2}$ and $\left.\mathrm{H}_{2} \mathrm{O}\right)$ towards and away from the catalytic sites located in the pores of the catalysts. This work further suggests the importance of morphology controls by using a novel template such as MOFs during the Fe-N-C catalyst design and synthesis. 

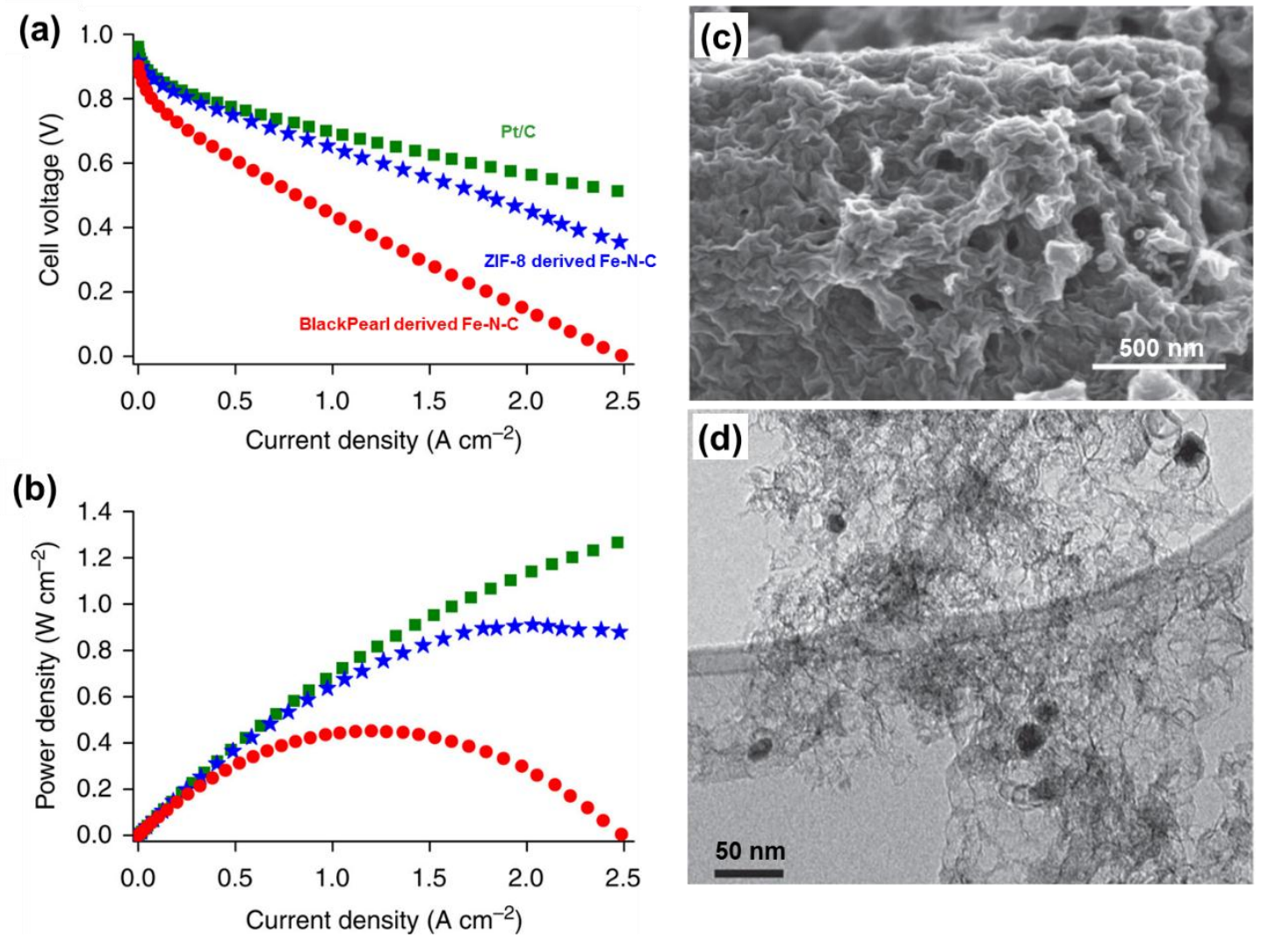

Figure 19. Polarization (a) and power density (b) curves of MEAs with the ironacetate/phenanthroline/zeolitic-imidazolate-framework (ZIF-8)-derived Fe-based and Pt-based cathodes. (c) Typical SEM and (d) TEM images for the highly active Fe-N-C catalysts. Reprinted with permission from Macmillan Publishers Ltd [Nature Communication] Ref. [143]. Copyright (2011).

Among the studied MOFs, ZIF-8 and ZIF-67 have attracted the most attention since they consist of abundant carbon, nitrogen ligands, and transition metals (Fe or $\mathrm{Co}$ ). In addition, they are easy to synthesize and have high surface and good chemical stability. Recently, many excellent M-N-C catalysts derived from these MOF have been reported [30,136,144]. Profound insights into the synthetic process particularly for the interactions between Fe and the ZIF-8 framework are certainly critical for generating more active sites with appropriate Fe- $\mathrm{N}$ 
coordination. Recently, we developed a new synthesis method for a highly active Fe-N-C catalyst featuring uniform Fe distribution at an atomic level. The novel synthesis starts with homogeneous doping of Fe into ZIF-8 followed by a simple one-step heat treatment. This synthesis method removes the need for tedious post-treatments such as acid leaching and the second heating treatment. The $\mathrm{FeN}_{4}$ structure in the Fe-doped ZIF-8 will facilitate the formation of the ORR active $\mathrm{FeN}_{x}$ sites during the thermal conversion process [145]. As $\mathrm{Zn}$ is volatile at high temperature and can be eliminated during pyrolysis, highly porous $\mathrm{N}$-doped carbon was generated [146,147]. Instead of highly graphitized nanocarbon, amorphous or partially graphitized carbon with two broad XRD peaks was observed in the catalyst. Notably, an $\mathrm{O}_{2}$-free environment for preparing the Fe-doped ZIF-8 precursor is found to be crucial for uniform $\mathrm{Fe}$ distribution with exceptionally improved ORR activity, exhibiting the highest half-wave potential $(0.82 \mathrm{~V} v s$. RHE) in acid. The remarkably enhanced activity is primarily due to the homogeneous Fe distribution at atomic level in 3D MOFs, which significantly increases the density of the ORR active Fe sites.

\subsection{ORR Active Site Debate}

As discussed above, the role of these metals in inducing active sites remains a subject of debate in the scientific community. Some specialists firmly believe that the metals correspond to an integral and electrochemically active part of the catalytic site, while others are of the opinion that the metal is merely a catalyst that promotes the formation of special nitrogen-doped carbon structures [40]. Lefèvre and coworkers synthesized a nanocomposite catalyst consisting of a mixture of phenanthroline and iron salts on carbon supports. In their work, it is believed that most of the catalytic active sites contain an iron cation coordinated by four pyridinic nitrogen configurations attached to the edges of graphitic sheets which belong to the carbon support [13]. 
This idea is in concordance with Yeager's claim on the role of transition metals in carbon-based catalysts. Essentially, Yeager's team concluded the outcomes of their polyacrylonitrile-based catalyst (PAN/Fe or Co) demonstrated that the addition of transition metals such as Fe and Co to nitrogen-doped carbon structures promoted the generation of pyridinic nitrogen thus providing binding sites for the transition metal ions to act as catalytic sites for oxygen reduction [148]. Bouwkamp-Wijnoltz et al. found that, after high temperature pyrolysis, only a small fraction of Fe- $\mathrm{N}_{4}$ sites were involved during the ORR $[149,150]$. Recently, using pyrolyzed model structures of iron porphyrins, Mukerjee et al., indicated that a covalent integration of the Fe- $\mathrm{N}_{\mathrm{x}}$ sites is embedded into $\pi$-conjugated carbon basal plane. The Fe- $\mathrm{N}_{\mathrm{x}}$ moieties have strong electron donating/withdrawing capability and significantly modify the electronic structure of adjacent carbon atoms, thereby improving ORR activity. Furthermore, they employed in-situ electrochemical X-ray spectroscopy methods to identify the various structural nature of the active sites in $\mathrm{Fe}-\mathrm{N}-\mathrm{C}$ catalysts. It was found that the single site $2 \mathrm{e}^{-}+2 \mathrm{e}^{-}$mechanism in alkaline media and the primary $\mathrm{Fe}^{2+}-\mathrm{N}_{4}$ centers and the dual-site $2 \mathrm{e}^{-}+2 \mathrm{e}^{-}$mechanism in acid media. A mechanism that surface bound coexisting $\mathrm{Fe} / \mathrm{Fe}_{\mathrm{x}} \mathrm{O}_{\mathrm{y}}$ nanoparticles (NPs) as the secondary active sites was proposed [151-156].

Another interesting approach to view the nature of the active sites within the catalyst's nanostructure is taken by Oh and Kim [157], where they propose that the metal itself does not behave as an active site. It is acknowledged that the transition metal plays a significant role during the oxygen reduction reaction. Not only does it promote the formation of active nitrogen functional groups but it also increases ORR activity [157]. This is particularly true in instances where cobalt salts are utilized due to the fact that Co-N-C catalysts behave similarly to the "metal-free" N-C catalysts in term of onset potentials and Tafel slopes of their ORR polarization 
plots The resulting data from the inductively coupled plasma-atomic emission spectroscopy (ICP-AES) characterization techniques along with electrochemical testing supports Oh and Kim's statement on the function of transition metals. Moreover, the X-ray photoelectron spectroscopy (XPS) characterization supports that the relatively content of pyridinic nitrogen strongly depends on the amount of transition metal salt added during the preparation of the sample catalyst $[41,157]$. That is, the transition metal salt acts as an essential synthetic precursor that contributes to the development of active sites. Gong et al., prepared a metal-free catalyst for ORR catalysis by pyrolyzing iron (II) phthalocyanine. The XPS analysis of the authors' vertically aligned nitrogen-containing carbon nanotubes (VA-NCNTs) catalyst was unable to detect Fe signals, which suggests that the residual metal catalyst was entirely removed during the acid leaching step. The results of the material characterization techniques led the authors to believe that the transition metal acted exclusively as a precursor and had no role on the active site of their catalyst $[14,150]$.

The controversy around the involvement of transition metals in the active sites mainly stems from the nature of the characterizing techniques used to elucidate the mechanism. The difficulties of obtaining in-situ data with high precision and sensitivity have been the main source of disagreement among the field. Although many may seek a general theory for the active site, it is very likely that the species involved in the active sites are dependent on the synthetic strategy and precursors. Hence, it may not be feasible to establish a general theory stating whether transition metals are active sites during oxygen reduction. What is evident is that transition metals boost the catalytic activity of these carbon composites either by increasing the BET surface area, promoting pyridinic and graphitic nitrogen content, anchoring the oxygen molecule to the carbon support or activating the nitrogen content with its intrinsic Lewis acid 
nature. It is very likely that transition metals reconfigure the electronic environment of the carbon planes in a way that lowers the overpotential and improves the kinetics of the oxygen reduction. The third possibility of a new iron-based catalytic site for the ORR could be a configuration consisting of outer graphitic layers encasing a $\mathrm{Fe}_{3} \mathrm{C}$ core [158]. This is due to an experimental result, in which highly active Fe-based catalysts were prepared with dominant $\mathrm{Fe}_{3} \mathrm{C}$ particles surrounded by a few layered graphic shells without any doped nitrogen. However, more extensive characterization of the new $\mathrm{Fe}_{3} \mathrm{C}$ catalyst is required to elucidate the ORR activity and catalyst chemical properties [158]. Notably, the optimal active site for the ORR is likely different in acidic, alkaline, and nonaqueous electrolytes [159]. A comprehensive discussion concerning the possible NPMC active site structures for the ORR can be found in relevant articles [160,161].

\subsection{Remaining Challenges of M-N-C Catalysts for the ORR}

Although transition metal dopants offer an effective catalyst, these catalysts tend to undergo fast performance degradation under standard testing operations that involve a constant voltage higher than 0.6 V [162]. According to Shui et al., [24], this durability issue is attributed to the fact that transition metals undergo corrosion which not only compromises the performance of the catalyst but also contaminates the fuel cell. In an attempt to address this problem, they rationally designed a nano-composite catalyst consisting of nitrogen-doped carbon nanotubes (VANCNTs), exhibiting superior stability in both acidic and alkaline media. These findings might appear counterintuitive to some, since it has been previously proposed by multiple studies that nitrogen-doped carbon catalysts prepared without any metal precursors exhibited much worse catalytic performance for reducing oxygen in acidic media than in alkaline electrolytes [150]. Therefore, it may still be debatable to conclude that one type of catalyst, either metal-free or transition-metal doped, dominates over the other. While transition-metal carbon based catalysts 
present better performance, metal-free catalysts are both more stable and durable. These results lead to the conclusion that further studies on both catalysts need to be carried out in order to broaden the current knowledge and understanding of their mechanisms. In regard to the most promising Fe-N-C catalysts, insufficient stability is the greatest challenge for Nafion ${ }^{\circledR}$-based acidic PEFC applications especially at high voltages (>0.6 V). Thus, accelerated durability tests have been extensively employed in the NPMC research community to study catalyst stability. Testing protocols for both aqueous solution-based RDE and Nafion ${ }^{\circledR}$-based MEA were developed by using potential/voltage cycling. At first, a potential cycling at $0.6-1.0 \mathrm{~V}$ vs RHE in an $\mathrm{O}_{2}$ saturated electrolyte (e.g., $0.5 \mathrm{M} \mathrm{H}_{2} \mathrm{SO}_{4}$ or $\left.0.1 \mathrm{M} \mathrm{NaOH}\right)$ at room temperature was used in RDE to determine catalyst stability. It should be noted that most Fe-N-C catalysts are stable in $\mathrm{O}_{2}$-free electrolytes during such potential cycling tests, however they are not stable in more practical $\mathrm{O}_{2}$-saturaed environments. Furthermore, in MEA fuel cell performance studies, voltage cycling between $0.6-1.0 \mathrm{~V}$ using $\mathrm{H}_{2} /$ air at $80^{\circ} \mathrm{C}$ was suggested to study the NPMC stability in a real fuel cell environment.

Another substantial challenge during the development of high-performance NPMCs is the successful transition of high catalyst activity determined from RDE to a high-performance MEA in fuel cells. Fundamental RDE tests are very important to study the intrinsic activity, fourelectron selectivity, and stability in aqueous electrolytes. However, well-established three-phase interfaces (solid-gas-liquid) within air cathodes are critical to generating sufficient and stable current density with mitigated water flooding impact. Therefore, besides intrinsic ORR activity of active sites, porous structures, hydrophilicity/hydrophobicity, and electrical conductivity governed by catalyst morphologies and surface chemistry are also key factors to affect overall fuel cell performance [163]. In addition, the ratios of ionomer (e.g., Nafion $\left.{ }^{\circledR}\right)$ and NPMC will 
also control the performance in both kinetic and mass transfer ranges. More importantly, optimal Nafion ${ }^{\circledR}$ content in air cathodes varied with catalyst properties such as surface areas, tapping density, and pore distribution. In addition, durability becomes more of a challenge in air cathodes when compared to aqueous electrolyte, because operation temperature increases to $80^{\circ} \mathrm{C}$ and $\mathrm{O}_{2}$ concentration elevates. Notably, despite the generally low $\mathrm{H}_{2} \mathrm{O}_{2}$ yields $(<5 \%)$ usually measured with most of Fe-N-C catalysts, it is still possible that active ORR sites can be affected by hydrogen peroxide. $\mathrm{H}_{2} \mathrm{O}_{2}$ may be locally rich at large quantities as a result of complex processes occurring at the three-phase interface in fuel cell cathode involving variations in temperature, humidity and $\mathrm{O}_{2}$ concentration. Thus, possible Fenton agents will significantly oxidize catalysts, ionomers, and membranes, resulting in serious degradation in fuel cell performance $[164,165]$. Detailed description of NPMCs as alternative cathodes in PEFC can be found in the relevant articles [166,167].

\section{Carbon Composites for Hybrid Pt ORR Catalysts}

In the last decade, substantial progress has been made in the synthesis and performance improvements of NPMCs, however their current activity and long-term durability, especially in more harsh acid media still are not sufficient for pracitcal applications. Pt-based catalysts remain the most effective way to facilitate the ORR in acidic electrolytes for current fuel cell technologies [168]. To fully take advantages of current NPMC achievements, some researhers, including Popov $[169,170]$ and ourseleves [36,43], have proposed a new concept to develop hybrid cathode catalysts consisting of highly ORR-acive carbon composites and well-despersed Pt or other precious metals (e.g., Ag) [171]. The motivation is to significantly reduce the $\mathrm{Pt}$ amounts and improve Pt activity and stability for real fuel cell applications. Among various carbon composite NPMCs, the highly graphitized carbon nanostructures present in the Fe-N-C 
catalysts may serve as a matrix for supporting Pt nanoparticles due to obvious advantages of high electronic conductivity and enhanced corrosion resistance as well as abundant $\mathrm{CN}_{x}$ and $\mathrm{FeN}_{x}$ actives sites.

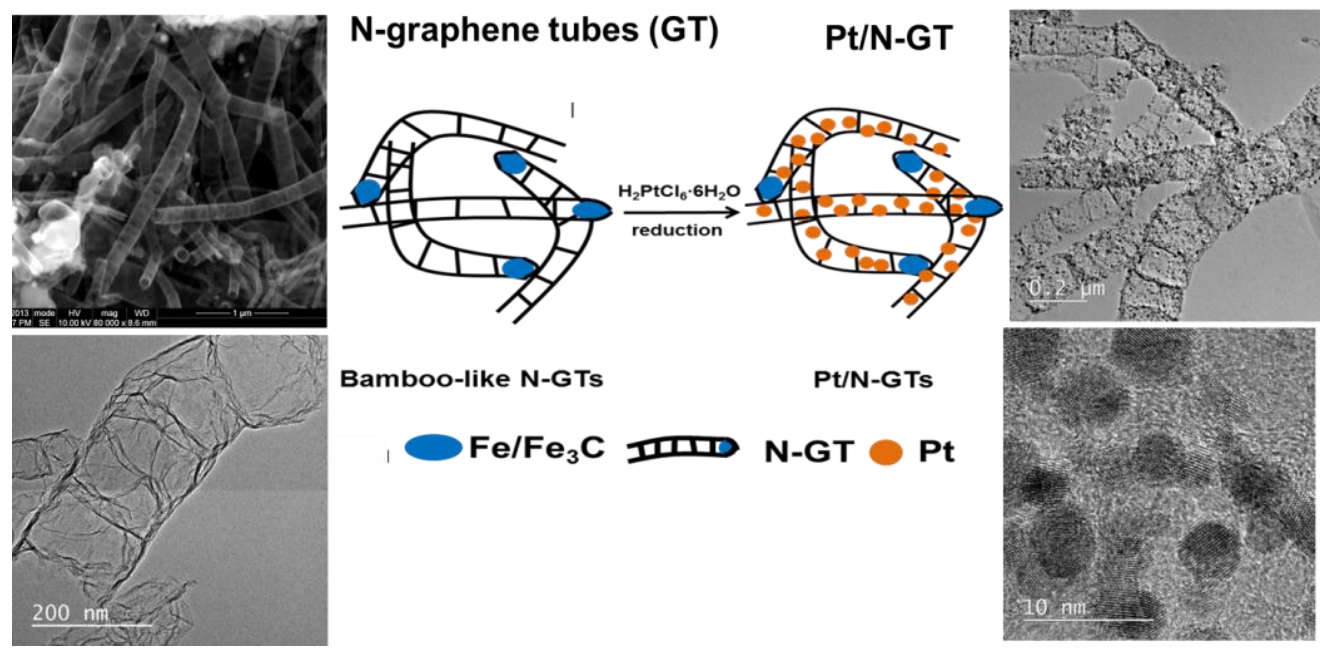

Figure 20. Synthetic scheme and microscopic images for hybrid Pt catalysts supported on nitrogen-doped graphene tubes. Reprinted from Ref. [43] with permission from WILEY-VCH.

As shown in Figure 20 [43], we recently developed a method to prepare highly active and stable Pt hybrid ORR catalysts by innovatively coupling Pt nanoparticles and highly active graphene tubes (up to $500 \mathrm{~nm}$ )-based Fe-N-C materials. The large-diameter nitrogen-doped graphene tubes (N-GTs) are derived from dicyandiamide (DCDA) and iron acetate via a high temperature method, which has exhibited high ORR activity. Therefore, from the catalyst design point of view, the ORR-active graphene tube support is able to not only offer a remarkable support effect by geometrically and electronically modifying the loaded Pt particles due to the nitrogen doping and highly graphitic surface, but it also provides a large amount of highly active non-precious metal active sites for the ORR. Both will significantly benefit the hybrid Pt catalsyt with imporved activity and durability. In particular, the doped nitrogen atoms is likely to attract 
electron from loaded Pt nanoparticles, evideneced by shifts of N 1s XPS peaks to low binding energy direction [43], suggesting an electron exchange between supports and metal particles [172]. In addition, compared to traditional carbon nanotube supports [173], the large size of NGTs (up to $500 \mathrm{~nm}$ ) provides a better platform than common carbon nanotubes $(<30 \mathrm{~nm}$ ), thus favorably anchoring and dispersing Pt nanoparticles.

As a result, the unique Pt/N-GT hybrid materials were found to provide excellent performance that is superior to commercial Pt/C catalyst as evidenced by both $\mathrm{RDE}$ and fuel cell tests (Figure 21a and b) [43]. The observed enhancements are likely due to the complementary ORR active sites on N-GTs, their highly graphitized structure formed during the hightemeprature heat treatment process, and favourable interactions between the nitrogen dopant species and Pt nanoparticles. Besides the enhanced activity, the significantly improved stability is important for the hybrid catalyst. In the case of traditional Pt/XC-72 catalyst, significant activity loss during the potential cycling (0.6-1.0 V) was found; this resulted from the obvious $\mathrm{Pt}$ particle agglomeration during cycling [89]. In contrast, as shown in Figure 21c, the N-GT support is able to stabilize Pt nanoparticles showing insignificant activity loss under identical potential cycling tests. Notably, a possible electron exchange between Pt and doped nitrogen has been identified due to a shift of graphitic N 1s spectroscopy to lower binding energy direction [43]. Thus, this hybrid concept presents a novel strategy to develop new carbon nanomaterials with improved ORR activity and reduced Pt contents for fuel cell applications. Further developments of hybrid catalysts require continuously optimizing the integration of highly active NPMCs with well-dispersed Pt alloy nanoparticles. In addition, one of the challenges for the development of Fe-containing hybrid catalysts is the stability of NPMC. Due to the possible 
formation of Fenton agents, other metal-derived formulations such as $\mathrm{Co} / \mathrm{Ni}-\mathrm{N}-\mathrm{C}$ probably are more appropriate.

(a)

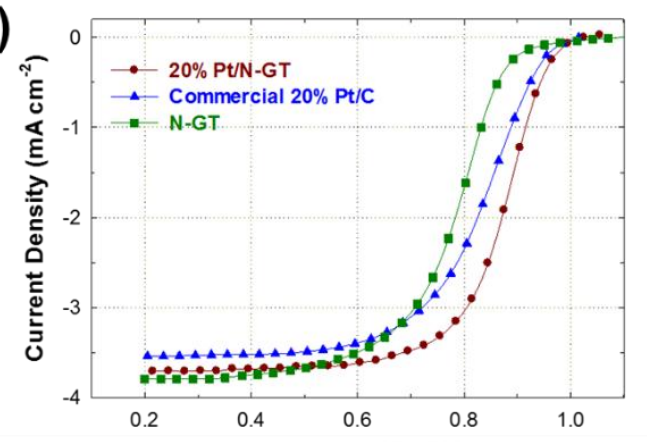

(b)

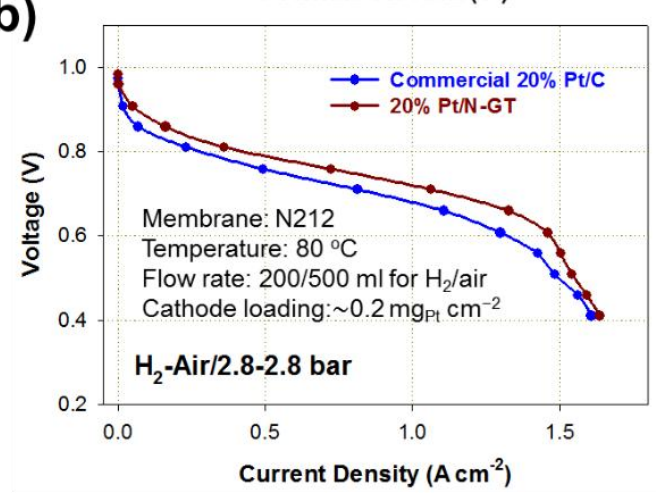

(c)
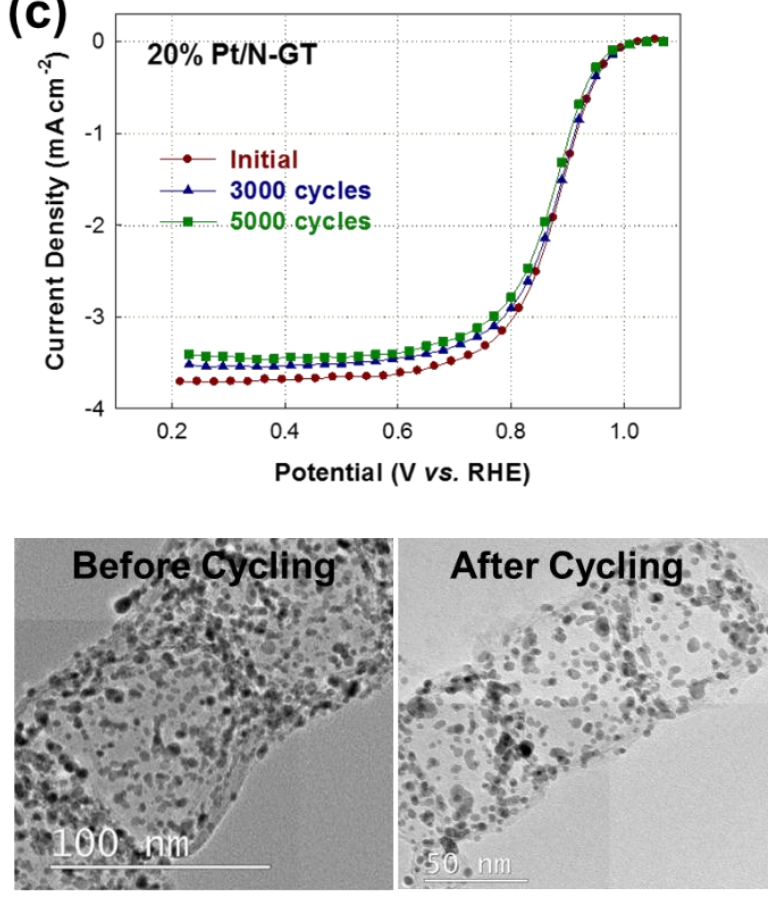

Figure 21. ORR steady-state RDE (a) and fuel cell (b) polarization curves recorded with the hybrid Pt/NGT. The Pt loadings for the RDE and fuel cell tests are $20 \mu \mathrm{g} / \mathrm{cm}^{2}$ and $0.2 \mathrm{mg} / \mathrm{cm}^{2}$, respectively. (c) enhanced potential cycling (0.6-1.0 V vs RHE) stability and TEM images of Pt/N-GT before and after 5,000 potential cycles. Reprinted from Ref. [43] with permission from WILEY-VCH.

\section{Bifunctional ORR/OER Carbon Composite Catalysts}

Beyond the heavily studied ORR catalysts, bifunctional transition-metal and "metal-free" ORR/OER catalysts have attracted substantial attention recently due to increasing demands to develop reversible electrochemical energy storage and conversion technologies such as utilized reversible fuel cells and rechargeable metal-air batteries. These reversible electrochemical energy technologies greatly rely on catalyst performance for the ORR and the OER. Like the ORR, the OER is a sluggish reaction and requires catalysts containing large amount of precious 
metals such as Ir or Ru to enhance the reaction activity and durability [174]. Even worse, highly ORR active Pt is not a good catalyst anymore for the OER due to formation of Pt oxides at high potentials. Likewise, OER active Ir is not a good catalyst for the ORR. Compared to the ORR, the OER is even more challenging due to the extremely oxidative conditions at high potentials (>1.4 V vs. RHE) [4]. Here, most of the currently studied carbon-based catalysts tend to degrade due to the rapid oxidation of carbon. Thus, the development of highly efficient and robust ORR/OER bifunctional catalysts derived from earth abundant elements is a necessity for such energy conversion and storage requirements.

It is well known that carbon can thermodynamically corrode above $0.207 \mathrm{~V}$ to carbon dioxide, and corrosion currents reach significant levels when operating during the OER above 1.3 V. However, highly graphitized nanocarbons with proper structures still hold promise that they can be used for OER catalysts, especially in less harsh alkaline media [175]. As shown in Figure 22 [175], a high-surface-area $\left(1,663 \mathrm{~m}^{2} \mathrm{~g}^{-1}\right)$ bifunctional nanocarbon catalyst consisting of a mesoporous carbon foam co-doped with nitrogen and phosphorus was reported recently to demonstrate good electrocatalytic activity simultaneously for the ORR and the OER. This carbon catalyst was prepared using a scalable one-step process involving the pyrolysis of PANI that is polymerized into a three-dimensional hydrogel crosslinked with phytic acids. As each phytic acid molecule can complex with up to six aniline monomers, phytic acid can be used as the crosslinker and protonic dopant to directly form the three-dimensional PANI hydrogel network, which is crucial for yielding high surface areas and accommodating more active sties. Density functional theory calculations further revealed that the isolated N-doped, the isolated P-doped, and the N/P-coupled structures located in the graphene planes were identified as ORR and OER active sites based on the studies of the volcano plot (Figure 22c and d). In particular, apart from 
ORR activity, the co-doped N/P structure is especially active with respect to the OER with the lowest overpotentials; they are even lower than that of the best metal-based catalyst identified theoretically $\left(\right.$ e.g., $\left.\mathrm{RuO}_{2}\right)$. This work suggests that proper doping of heteroatoms into carbon will provide a new opportunity to design ORR/OER bifunctional nanocarbon catalysts.
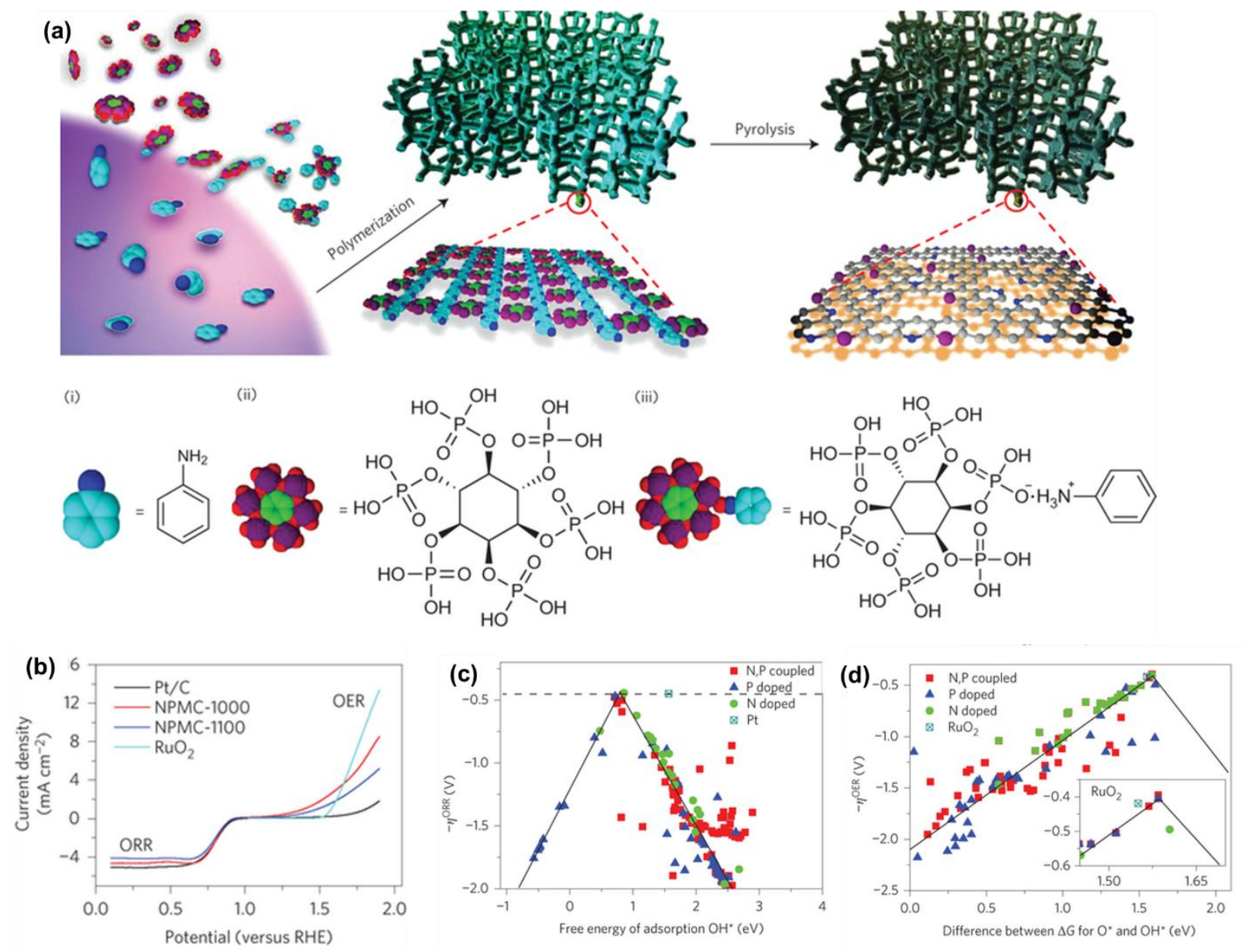

Figure 22. (a) Schematic illustration of the preparation process for the mesoporous carbon foams with $\mathrm{N}$ and P co-doping. (b) LSV curves of NPMC-1000, NPMC-1100, $\mathrm{RuO}_{2}$ and commercial Pt/C catalyst on an $\operatorname{RDE}(1,600 \mathrm{rpm})$ in $0.1 \mathrm{M} \mathrm{KOH}$ (scan rate, $5 \mathrm{mVs}^{-1}$ ), showing the electrocatalytic activities for both ORR and OER. ORR (c) and OER (d) volcano plots of overpotential $\eta$ versus adsorption energy of O* and the difference between the adsorption energy of $\mathrm{O}^{*}$ and $\mathrm{OH}^{*}$, respectively, for $\mathrm{N}$-doped, $\mathrm{P}$-doped and N, P-doped graphene. Reprinted with permission from Macmillan Publishers Ltd [Nature Nanotechnology] Ref. [175]. Copyright (2015). 
Usually, as the optimal active-site structures for the ORR and the OER are not similar, bifunctional catalysts contain two or more constituents. Therefore, during nanocarbon-based catalyst design, a special emphasis has been put on nanocarbon/oxide (sulfide) nanocomposites, consisting of ORR active nanocarbon and OER active oxides or sulfides to catalyze different electrochemical reactions [176-179]. In particular, relative to conventional carbon materials, transition metal oxides/sulfides are inherently more stable than carbon in oxidizing environments and are more active for the OER [180]. They can be deposited onto ORR active nitrogen-doped nanocarbon supports such as graphene or carbon nanotubes. Meanwhile, ORR active nanocarbon are porous and highly graphitic, so they will provide efficient electron transfer pathways and mass transport channels to the OER active species. In our recent effort, $\mathrm{Mn}_{3} \mathrm{O}_{4}$ nanoparticles have been successfully deposited onto graphene, showing promising charging and discharging performances in Li-air batteries. In turn, these metal oxides can serve as substrates or templates for the synthesis of $\mathrm{N}$-doped nanocarbons [39,123]. Following these concepts, the possible synergistic effects occurring between the ORR and OER components may play a beneficial role in maximizing activity and durability of bifunctional catalysts. Further investigations for different metal oxides and nanocarbon supports, along with interface engineering, will yield novel ORR/OER bifunctional nanocomposite catalysts for reversible electrochemical energy technologies.

\section{Summary and Perspective}

These highly demanding electrochemical clean energy technologies greatly rely on electrocatalysis of the oxygen reduction and oxygen evolution reactions. Large amounts of Pt or Ir used for catalysts prohibitively limits the widespread implementation of these energy conversion and storage technologies. Therefore, development of cost-effective and robust 
electrocatalysts derived from earth-abundant elements for these oxygen reactions has become an important research topic from both fundamental and applied research points of view. Among the studied catalyst formulations, "metal-free" and transition metals involved heteroatom-doped carbon composites hold great promise to replace Pt in near future in terms of their exceptionally improved activity in both alkaline and acidic electrolyte. However, their eventually practical applications, particularly in acidic fuel cells, still require significant effort to address current issues such as insufficient activity and performance durability. Therefore, significant gaps between the most active Fe-N-C and state-of-the-art Pt/C catalysts must be bridged for viable applications. Importantly, due to thermaldymantically unstable nature of carbon materials (above $0.2 \mathrm{~V}$ in the presence of water), PEFC performance losses are largely related to the deterioration of the cathode carbon catalysts, especially during start-up/shut-down under the stringent conditions of automotive operation. Likewise, a grand challenge facing the OER catalysts is the very likely carbon oxidation/corrosion. Thus, identifying highly stable nanocarbons even at high potential $(>1.6 \mathrm{~V})$ will be extremely crucial for utilizing carbon as a robust ORR/OER bifunctional catalysts for reversible electrochemical devices. Recently, we have discovered that tube structures is more stable compared to other carbon structures, providing opportunity to integrate highly ORR-active N-C or M-N-C components with OER-active oxides [177].

In this review, we elucidate synthesis-structure-property correlations during the catalyst developments, which is very valuable to help us continuously design and prepare advanced catalyst with improved activity and durability. Two types of carbon materials hold great promise to replace precious metals in the future for fuel cell and other electrochemical energy applications. They are "metal-free" heteroatom (e.g., N)-doped carbon catalysts (C-N) and nitrogen- and transition metal-"co-doped" carbon catalysts (M-N-C, M=Fe or/and Co). While transition-metal 
carbon based catalysts present a better performance, metal-free catalysts are both more stable and durable. Therefore, further studies on both catalysts need to be carried out in order to broaden the current knowledge and understanding of their mechanisms and only then decide which catalyst is more appropriate for different applications either in alkaline or acidic media.

The nanostructures and morphologies (e.g., surface areas, porosity, and graphitization) of graphitized carbon during the high-temperature treatment is greatly dependent on the employed transition metals, nitrogen-carbon precursors, and synthetic procedures, which directly link to the catalytic activity. The carbon nanostructures (e.g., tubes, onion-like carbon, and multiple-layered graphene) once were observed in highly active $\mathrm{M}-\mathrm{N}-\mathrm{C}$ catalysts. Therefore, we speculated that the in situ formation of highly graphitized nanocarbon structures in the $\mathrm{M}-\mathrm{N}-\mathrm{C}$ catalysts seems to be a critical factor dictating active site generation and is directly linked to the observed ORR activity. The role of carbon structures in the M-N-C catalyst seems to be very crucial and serve as either an active species or a matrix to accommodate active species. Due to nitrogen and transition metal doping, the inactive carbon atoms surrounding these dopant may become very active for oxygen reduction or evolution reactions. However, in our recent effort to develop the Fe-N-C catalyst derived from MOFs, dominant amorphous carbon (or only partial graphitization) morphology with uniform distribution of atomic $\mathrm{N}$ and $\mathrm{Fe}$ was found in a new type of Fe-N-C catalysts showing even higher ORR activity ( $E_{1 / 2}$ up to $0.82 \mathrm{~V}$ vs RHE) and stability relative to state-of-the-art graphitized carbon-rich Fe-N-C catalysts $(0.80 \mathrm{~V})$. Thus, it seems that the highly graphitized carbon structures in the M-N-C catalysts are not necessary for generating high ORR activity. The discrepancy continuously puzzles us in terms of the optimal carbon structures in the M-N-C catalysts for the ORR. Thus, elucidating the role of carbon structures at atomic level and 
local bonding environment of carbon are fundamentally important to predict and design optimal M-N-C catalysts

Meanwhile, further performance improvement requires novel concepts to design catalysts with intimate interaction among transition metal, nitrogen, and carbon during the processing precursors (e.g., metal, nitrogen, carbon, and template), heat-treating, and post-treatments. High surface area with mesoscale pore structures in a 3D architecture will increase density of active sites, generating high current density. Selection of advanced supporting materials or templates such as graphene and MOFs may provide new opportunities on boosting the catalyst activity. Continuously improving activity and durability of catalysts requires understanding of the exact active site in catalysts. It is unclear whether the transition metals is the crucial center of the active site(s), or if it only catalyzes the process of nitrogen doping into carbon. In addition, the bonding mechanism and optimal structures of nitrogen and carbon (e.g., in-plane, edge, subsurface) are yet to be conclusively identified. In addition, an ideal active site on the top of the volcano for the ORR will be not on the top of the OER volcano. Intrinsically, a single site cannot simultaneously active for the ORR and the OER. Therefore, developing a so-called bifunctional electrocatalysts needs to wisely integrate both types of sites into a carbon nanocomposite. Therefore, these puzzles in the field of NPMC electrocatalysis will motivate researchers to focus on elucidation of the role of the nitrogen, carbon, and transition metal for rational design and synthesis of advanced M-N-C catalysts. As direct probing the active sites on the top layers of catalyst surface is very challenging, theoretical calculation and simulation are powerful tools to provide insights into the origin of active sites. Solving these puzzles is essential to the development of highly active, selective, and stable NPMCs for clean energy conversion and storage. 


\section{Acknowledgements}

G. W. acknowledges the financial support from the start-up Funds of University at Buffalo along with U.S. Department of Energy, Fuel Cell Technologies Office (FCTO) Incubator Program (DE-EE000696). L. D. thanks for the financial supports from NSF (CMMI-1400274, CMMI1266295), and DOD-AFOSR-MURI (FA9550-12-1-0037). H-L Wang is grateful to the support from Laboratory Directed Research \& Development (LDRD) program at Los Alamos National Laboratory.

\section{References}

[1] U. Eberle, R. von Helmolt, Energy Environ. Sci., 3 (2010) 689-699.

[2] C. Budischak, D. Sewell, H. Thomson, L. Mach, D.E. Veron, W. Kempton, J. Power Sources, 225 (2013) 60-74.

[3] T.R. Cook, D.K. Dogutan, S.Y. Reece, Y. Surendranath, T.S. Teets, D.G. Nocera, Chem. Rev., 110 (2010) 6474-6502.

[4] S. Gupta, W. Kellogg, H. Xu, X. Liu, J. Cho, G. Wu, Chem. An Asian J., (2015) DOI:

10.1002/asia.201500640.

[5] Z. Yang, J. Zhang, M.C. Kintner-Meyer, X. Lu, D. Choi, J.P. Lemmon, J. Liu, Chem. Rev., 111 (2011) 3577-3613.

[6] B. Dunn, H. Kamath, J.-M. Tarascon, Science, 334 (2011) 928-935.

[7] H.D. Yoo, E. Markevich, G. Salitra, D. Sharon, D. Aurbach, Mater. Today, 17 (2014) 110-121.

[8] Y. Zheng, Y. Jiao, S.Z. Qiao, Adv. Mater., 27 (2015) 5372-5378.

[9] A. Rabis, P. Rodriguez, T.J. Schmidt, ACS Catal., 2 (2012) 864-890.

[10] M.K. Debe, Nature, 486 (2012) 43-51.

[11] G. Wu, K.L. More, C.M. Johnston, P. Zelenay, Science, 332 (2011) 443-447.

[12] J. Suntivich, K.J. May, H.A. Gasteiger, J.B. Goodenough, Y. Shao-Horn, Science, 334 (2011) 13831385.

[13] M. Lefèvre, E. Proietti, F. Jaouen, J.-P. Dodelet, Science, 324 (2009) 71-74.

[14] K. Gong, F. Du, Z. Xia, M. Durstock, L. Dai, Science, 323 (2009) 760-764.

[15] F. Jaouen, E. Proietti, M. Lefèvre, R. Chenitz, J.-P. Dodelet, G. Wu, H.T. Chung, C.M. Johnston, P. Zelenay, Energy Environ. Sci., 4 (2011) 114-130.

[16] G. Wu, G. Cui, D. Li, P.-K. Shen, N. Li, J. Mater. Chem., 19 (2009) 6581-6589.

[17] B. Wang, J. Power Sources, 152 (2005) 1-15.

[18] Q. Li, P. Xu, B. Zhang, H. Tsai, S. Zheng, G. Wu, H.-L. Wang, J. Phys. Chem. C, 117 (2013) 1387213878.

[19] X. Wang, Y. Ke, H. Pan, K. Ma, Q. Xiao, G. Wu, M.T. Swihart, ACS Catalysis, 5 (2015) 2534-2540.

[20] H. Yin, C. Zhang, F. Liu, Y. Hou, Adv. Func. Mater., 24 (2014) 2930-2937.

[21] C. Wei, L. Yu, C. Cui, J. Lin, C. Wei, N. Mathews, F. Huo, T. Sritharan, Z. Xu, Chem. Commun., 50 (2014) 7885-7888.

[22] J. Zhang, L. Dai, ACS Catal., (2015) 7244-7253. 
[23] L. Qu, Y. Liu, J.-B. Baek, L. Dai, ACS Nano, 4 (2010) 1321-1326.

[24] J. Shui, M. Wang, F. Du, L. Dai, Sci. Adv., 1 (2015) e1400129.

[25] L. Dai, Y. Xue, L. Qu, H.-J. Choi, J.-B. Baek, Chem. Rev., (2015).

[26] H. Liu, Y. Zheng, G. Wang, S.Z. Qiao, Adv. Energy Mater., 5 (2015).

[27] V. Nallathambi, J.-W. Lee, S.P. Kumaraguru, G. Wu, B.N. Popov, J. Power Sources, 183 (2008) 34-42.

[28] N.P. Subramanian, X. Li, V. Nallathambi, S.P. Kumaraguru, H. Colon-Mercado, G. Wu, J.-W. Lee, B.N. Popov, J. Power Sources, 188 (2009) 38-44.

[29] V. Nallathambi, G. Wu, N. Subramanian, S. Kumaraguru, J.-W. Lee, B. Popov, ECS Trans., 11 (2007) 241-247.

[30] Q. He, Q. Li, S. Khene, X. Ren, F.E. López-Suárez, D. Lozano-Castelló, A. Bueno-López, G. Wu, J. Phys. Chem. C, 117 (2013) 8697-8707.

[31] Q. Li, G. Wu, D.A. Cullen, K.L. More, N.H. Mack, H.T. Chung, P. Zelenay, ACS Catal., 4 (2014) 31933200.

[32] Q. Li, R. Cao, J. Cho, G. Wu, Phys. Chem. Chem. Phys., 16 (2014) 13568-13582.

[33] Q. Li, P. Xu, B. Zhang, H. Tsai, J. Wang, H.-L. Wang, G. Wu, Chem. Commun., 49 (2013) 10838-10840.

[34] G. Wu, Z.W. Chen, K. Artyushkova, F.H. Garzon, P. Zelenay, ECS Trans., 16 (2008) 159-170.

[35] G. Wu, K. Artyushkova, M. Ferrandon, A.J. Kropf, D. Myers, P. Zelenay, ECS Trans., 25 (2009) 12991311.

[36] G. Wu, C.S. Dai, D.L. Wang, D.Y. Li, N. Li, J. Mater. Chem., 20 (2010) 3059-3068.

[37] G. Wu, C.M. Johnston, N.H. Mack, K. Artyushkova, M. Ferrandon, M. Nelson, J.S. Lezama-Pacheco, S.D. Conradson, K.L. More, D.J. Myers, P. Zelenay, J. Mater. Chem., 21 (2011) 11392-11405.

[38] J. Xiao, D. Mei, X. Li, W. Xu, D. Wang, G.L. Graff, W.D. Bennett, Z. Nie, L.V. Saraf, I.A. Aksay, J. Liu, J.G. Zhang, Nano Lett., 11 (2011) 5071-5078.

[39] G. Wu, M.A. Nelson, N.H. Mack, S.G. Ma, P. Sekhar, F.H. Garzon, P. Zelenay, Chem. Commun., 46 (2010) 7489-7491.

[40] G. Wu, P. Zelenay, Acc. Chem. Res., 46 (2013) 1878-1889.

[41] G. Wu, N.H. Mack, W. Gao, S. Ma, R. Zhong, J. Han, J.K. Baldwin, P. Zelenay, ACS Nano, 6 (2012) 9764-9776.

[42] Q. He, G. Wu, K. Liu, S. Khene, Q. Li, T. Mugadza, E. Deunf, T. Nyokong, S.W. Chen, ChemElectroChem, 1 (2014) 1508-1515.

[43] Q. Li, H. Pan, D. Higgins, R. Cao, G. Zhang, H. Lv, K. Wu, J. Cho, G. Wu, Small, 11 (2015) 1443-1452.

[44] K. Parvez, S. Yang, Y. Hernandez, A. Winter, A. Turchanin, X. Feng, K. Müllen, ACS Nano, 6 (2012) 9541-9550.

[45] H.R. Byon, J. Suntivich, Y. Shao-Horn, Chem. Mater., 23 (2011) 3421-3428.

[46] L. Lai, J.R. Potts, D. Zhan, L. Wang, C.K. Poh, C. Tang, H. Gong, Z. Shen, J. Lin, R.S. Ruoff, Energy Environ. Sci., 5 (2012) 7936-7942.

[47] Y. Li, W. Zhou, H. Wang, L. Xie, Y. Liang, F. Wei, J.-C. Idrobo, S.J. Pennycook, H. Dai, Nat. Nanotechnol., 7 (2012) 394-400.

[48] J.L. Shui, N.K. Karan, M. Balasubramanian, S.Y. Li, D.J. Liu, J. Am. Chem. Soc., 134 (2012) 1665416661.

[49] S. Pylypenko, S. Mukherjee, T.S. Olson, P. Atanassov, Electrochim. Acta, 53 (2008) 7875-7883.

[50] H. Niwa, K. Horiba, Y. Harada, M. Oshima, T. Ikeda, K. Terakura, J.-i. Ozaki, S. Miyata, J. Power Sources, 187 (2009) 93-97.

[51] K. Mamtani, U.S. Ozkan, Catal. Lett., 145 (2015) 436-450.

[52] J.D. Wiggins-Camacho, K.J. Stevenson, J. Phys. Chem. C, 115 (2011) 20002-20010.

[53] F. Jaouen, V. Goellner, M. Lefèvre, J. Herranz, E. Proietti, J. Dodelet, Electrochim. Acta, 87 (2013) 619-628. 
[54] V. Nallathambi, N. Leonard, R. Kothandaraman, S.C. Barton, Electrochem. Solid-state Lett., 14 (2011) B55-B58.

[55] J. Wu, Z. Yang, X. Li, Q. Sun, C. Jin, P. Strasser, R. Yang, J. Mater. Chem. A, 1 (2013) 9889-9896.

[56] N. Ramaswamy, U. Tylus, Q. Jia, S. Mukerjee, J. Am. Chem. Soc., 135 (2013) 15443-15449.

[57] F. Jaouen, J. Herranz, M. Lefevre, J.-P. Dodelet, U.I. Kramm, I. Herrmann, P. Bogdanoff, J.

Maruyama, T. Nagaoka, A. Garsuch, ACS Appl. Mater. Interfaces, 1 (2009) 1623-1639.

[58] J. Liang, Y. Jiao, M. Jaroniec, S.Z. Qiao, Angew. Chem.-Int. Edit., 51 (2012) 11496-11500.

[59] Y. Jiao, Y. Zheng, M. Jaroniec, S.Z. Qiao, J. Am. Chem. Soc., 136 (2014) 4394-4403.

[60] S. Ganesan, N. Leonard, S.C. Barton, Phys. Chem. Chem. Phys., 16 (2014) 4576-4585.

[61] Y. Gong, H. Fei, X. Zou, W. Zhou, S. Yang, G. Ye, Z. Liu, Z. Peng, J. Lou, R. Vajtai, B.I. Yakobson, J.M. Tour, P.M. Ajayan, Chem. Mater., 27 (2015) 1181-1186.

[62] K. Strickland, E. Miner, Q. Jia, U. Tylus, N. Ramaswamy, W. Liang, M.-T. Sougrati, F. Jaouen, S. Mukerjee, Nat. Commun., 6 (2015) 7343.

[63] J. Liang, R.F. Zhou, X.M. Chen, Y.H. Tang, S.Z. Qiao, Adv. Mater., 26 (2014) 6074-6079.

[64] R. Zhou, S.Z. Qiao, Chem. Commun., 51 (2015) 7516-7519.

[65] D. Higgins, G. Wu, H.T. Chung, U. Martinez, S. Ma, Z. Chen, P. Zelenay, ECS Transactions, 61 (2014) 35-42.

[66] H.T. Chung, G. Wu, Q. Li, P. Zelenay, Int. J. Hydrogen Energy, 39 (2014) 15887-15893.

[67] J. Duan, S. Chen, M. Jaroniec, S.Z. Qiao, ACS Catal., 5 (2015) 5207-5234.

[68] H.T. Chung, J.H. Won, P. Zelenay, Nat. Commun., 4 (2013) 1922.

[69] Y.-J. Wang, N. Zhao, B. Fang, H. Li, X.T. Bi, H. Wang, Chemical Reviews, 115 (2015) 3433-3467.

[70] S. Koh, P. Strasser, Journal of the American Chemical Society, 129 (2007) 12624-12625.

[71] J. Wu, L. Qi, H. You, A. Gross, J. Li, H. Yang, J. Am. Chem. Soc., 134 (2012) 11880-11883.

[72] K. Sasaki, H. Naohara, Y. Choi, Y. Cai, W.-F. Chen, P. Liu, R.R. Adzic, Nat. Commun., 3 (2012) 1115.

[73] D. Wang, H.L. Xin, R. Hovden, H. Wang, Y. Yu, D.A. Muller, F.J. DiSalvo, H.D. Abruña, Nat. Mater., 12 (2013) 81-87.

[74] V.R. Stamenkovic, B.S. Mun, M. Arenz, K.J.J. Mayrhofer, C.A. Lucas, G. Wang, P.N. Ross, N.M. Markovic, Nat. Mater., 6 (2007) 241-247.

[75] B. Lim, M. Jiang, P.H.C. Camargo, E.C. Cho, J. Tao, X. Lu, Y. Zhu, Y. Xia, Science, 324 (2009) 13021305.

[76] P.H. Matter, L. Zhang, U.S. Ozkan, J. Catal., 239 (2006) 83-96.

[77] G. Wu, M. Nelson, S. Ma, H. Meng, G. Cui, P.K. Shen, Carbon, 49 (2011) 3972-3982.

[78] F. Calle-Vallejo, J.I. Mart?nez, J. Rossmeisl, Phys. Chem. Chem. Phys., 13 (2011) 15639-15643.

[79] J.R. Pels, F. Kapteijn, J.A. Moulijn, Q. Zhu, K.M. Thomas, Carbon, 33 (1995) 1641-1653.

[80] J. Zhang, Z. Xia, L. Dai, Sci. Adv., 1 (2015).

[81] S. Maldonado, S. Morin, K.J. Stevenson, Carbon, 44 (2006) 1429-1437.

[82] H. Kim, K. Lee, S.I. Woo, Y. Jung, Phys. Chem. Chem. Phys., 13 (2011) 17505-17510.

[83] W. Yuan, Y. Zhou, Y. Li, C. Li, H. Peng, J. Zhang, Z. Liu, L. Dai, G. Shi, Sci. Rep., 3 (2013) 2248.

[84] A. Shen, Y. Zou, Q. Wang, R.A.W. Dryfe, X. Huang, S. Dou, L. Dai, S. Wang, Angew. Chem.-Int. Edit., 53 (2014) 10804-10808.

[85] D. Wei, Y. Liu, Y. Wang, H. Zhang, L. Huang, G. Yu, Nano Lett., 9 (2009) 1752-1758.

[86] J. Lahaye, G. Nansé, A. Bagreev, V. Strelko, Carbon, 37 (1999) 585-590.

[87] G. Wu, D. Li, C. Dai, D. Wang, N. Li, Langmuir, 24 (2008) 3566-3575.

[88] G. Wu, R. Swaidan, D. Li, N. Li, Electrochim. Acta, 53 (2008) 7622-7629.

[89] Y. Shao, G. Yin, Y. Gao, J. Power Sources, 171 (2007) 558-566.

[90] G. Wu, Y.-S. Chen, B.-Q. Xu, Electrochem. Commun., 7 (2005) 1237-1243.

[91] G. Wu, R. Swaidan, G. Cui, J. Power Sources, 172 (2007) 180-188.

[92] G. Wu, L. Li, J.-H. Li, B.-Q. Xu, J. Power Sources, 155 (2006) 118-127. 
[93] M.D. Esrafili, Comp. Theor. Chem., 1015 (2013) 1-7.

[94] Q. Li, R. Cao, J. Cho, G. Wu, Adv. Energy Mater., 4 (2014) 1301415.

[95] T. Sharifi, G. Hu, X. Jia, T. Wågberg, ACS nano, 6 (2012) 8904-8912.

[96] C.V. Rao, C.R. Cabrera, Y. Ishikawa, J. Phys. Chem. Lett., 1 (2010) 2622-2627.

[97] D. Geng, S. Yang, Y. Zhang, J. Yang, J. Liu, R. Li, T.-K. Sham, X. Sun, S. Ye, S. Knights, Appl. Surf. Sci., 257 (2011) 9193-9198.

[98] Y. Shao, S. Zhang, M.H. Engelhard, G. Li, G. Shao, Y. Wang, J. Liu, I.A. Aksay, Y. Lin, J. Mater. Chem., 20 (2010) 7491-7496.

[99] X. Li, H. Wang, J.T. Robinson, H. Sanchez, G. Diankov, H. Dai, J. Am. Chem. Soc., 131 (2009) 1593915944.

[100] C. Zhang, L. Fu, N. Liu, M. Liu, Y. Wang, Z. Liu, Adv. Mater., 23 (2011) 1020-1024.

[101] Y. Zhao, C. Hu, Y. Hu, H. Cheng, G. Shi, L. Qu, Angew. Chem.-Int. Edit., 51 (2012) 11371-11375.

[102] F. Pan, J. Jin, X. Fu, Q. Liu, J. Zhang, ACS Appl. Mater. Interfaces, 5 (2013) 11108-11114.

[103] X. Bo, C. Han, Y. Zhang, L. Guo, ACS Appl. Mater. Interfaces, 6 (2014) 3023-3030.

[104] Z. Jin, J. Yao, C. Kittrell, J.M. Tour, ACS Nano, 5 (2011) 4112-4117.

[105] Z. Luo, S. Lim, Z. Tian, J. Shang, L. Lai, B. MacDonald, C. Fu, Z. Shen, T. Yu, J. Lin, J. Mater. Chem., 21 (2011) 8038-8044.

[106] D. Usachov, O. Vilkov, A. Grüneis, D. Haberer, A. Fedorov, V.K. Adamchuk, A.B. Preobrajenski, P. Dudin, A. Barinov, M. Oehzelt, C. Laubschat, D.V. Vyalikh, Nano Lett., 11 (2011) 5401-5407.

[107] L. Zhao, K.T. Rim, H. Zhou, R. He, T.F. Heinz, A. Pinczuk, G.W. Flynn, A.N. Pasupathy, Solid State Commun., 151 (2011) 509-513.

[108] Y. Xue, B. Wu, L. Jiang, Y. Guo, L. Huang, J. Chen, J. Tan, D. Geng, B. Luo, W. Hu, G. Yu, Y. Liu, J. Am. Chem. Soc., 134 (2012) 11060-11063.

[109] D. Long, W. Li, L. Ling, J. Miyawaki, I. Mochida, S.-H. Yoon, Langmuir, 26 (2010) 16096-16102.

[110] L. Sun, L. Wang, C. Tian, T. Tan, Y. Xie, K. Shi, M. Li, H. Fu, RSC Adv., 2 (2012) 4498-4506.

[111] D. Deng, X. Pan, L. Yu, Y. Cui, Y. Jiang, J. Qi, W.-X. Li, Q. Fu, X. Ma, Q. Xue, G. Sun, X. Bao, Chem.

Mater., 23 (2011) 1188-1193.

[112] W. Qian, X. Cui, R. Hao, Y. Hou, Z. Zhang, ACS Appl. Mater. Interfaces, 3 (2011) 2259-2264.

[113] L.S. Panchakarla, K.S. Subrahmanyam, S.K. Saha, A. Govindaraj, H.R. Krishnamurthy, U.V.

Waghmare, C.N.R. Rao, Adv. Mater., 21 (2009) 4726-4730.

[114] W. Zhao, O. Höfert, K. Gotterbarm, J.F. Zhu, C. Papp, H.P. Steinrück, J. Phys. Chem. C, 116 (2012)

5062-5066.

[115] I.-Y. Jeon, H.-J. Choi, M. Choi, J.-M. Seo, S.-M. Jung, M.-J. Kim, S. Zhang, L. Zhang, Z. Xia, L. Dai, N.

Park, J.-B. Baek, Sci. Rep., 3 (2013) 1810.

[116] W. Gao, G. Wu, M.T. Janicke, D.A. Cullen, R. Mukundan, J.K. Baldwin, E.L. Brosha, C. Galande, P.M. Ajayan, K.L. More, Angew. Chem. Int. Ed., 53 (2014) 3588-3593.

[117] W. Gao, L.B. Alemany, L. Ci, P.M. Ajayan, Nat. Chem., 1 (2009) 403-408.

[118] R.A. Sidik, A.B. Anderson, N.P. Subramanian, S.P. Kumaraguru, B.N. Popov, J. Phys. Chem. B, 110

(2006) 1787-1793.

[119] T.-P. Fellinger, F. Hasché, P. Strasser, M. Antonietti, J. Am. Chem. Soc., 134 (2012) 4072-4075.

[120] Y. Okamoto, Appl. Surf. Sci., 256 (2009) 335-341.

[121] D.C. Higgins, M.A. Hoque, F. Hassan, J.-Y. Choi, B. Kim, Z. Chen, ACS Catal., 4 (2014) 2734-2740.

[122] G.-L. Tian, M.-Q. Zhao, D. Yu, X.-Y. Kong, J.-Q. Huang, Q. Zhang, F. Wei, Small, 10 (2014) 2251-2259.

[123] Z. Chen, A. Yu, D. Higgins, H. Li, H. Wang, Z. Chen, Nano Lett., 12 (2012) 1946-1952.

[124] Y. Li, J. Wang, X. Li, D. Geng, M.N. Banis, R. Li, X. Sun, Electrochem. Commun., 18 (2012) 12-15.

[125] Y. Li, Z. Huang, K. Huang, D. Carnahan, Y. Xing, Energy Environ. Sci., 6 (2013) 3339-3345.

[126] Y. Mao, H. Duan, B. Xu, L. Zhang, Y. Hu, C. Zhao, Z. Wang, L. Chen, Y. Yang, Energy Environ. Sci., 5 (2012) 7950-7955. 
[127] Y. Shao, J. Sui, G. Yin, Y. Gao, Appl. Catal. B: Environ., 79 (2008) 89-99.

[128] Y. Nie, L. Li, Z. Wei, Chem. Soc. Rev., 44 (2015) 2168-2201.

[129] P. Zelenay, DOE EERE Annual Review Report, (2014).

[130] R. Jasinski, Nature 201 (1964) 1212-1213.

[131] Q. Li, P. Xu, W. Gao, S. Ma, G. Zhang, R. Cao, J. Cho, H.-L. Wang, G. Wu, Adv. Mater., 26 (2014) 1378-1386.

[132] G. Wu, H.T. Chung, M. Nelson, K. Artyushkova, K.L. More, C.M. Johnston, P. Zelenay, ECS Trans., 41 (2011) 1709-1717.

[133] M. Ferrandon, A.J. Kropf, D.J. Myers, K. Artyushkova, U. Kramm, P. Bogdanoff, G. Wu, C.M. Johnston, P. Zelenay, J. Phys. Chem. C, 116 (2012) 16001-16013.

[134] U.I. Koslowski, I. Abs-Wurmbach, S. Fiechter, P. Bogdanoff, J. Phys. Chem. C, 112 (2008) 1535615366.

[135] X.L. Wang, Q. Li, H. Pan, Y. Lin, Y. Ke, H. Sheng, M.T. Swihart, G. Wu, Nanoscale, 7 (2015) 2029020298.

[136] D. Zhao, J.-L. Shui, C. Chen, X. Chen, B.M. Reprogle, D. Wang, D.-J. Liu, Chem. Sci., 3 (2012) 32003205.

[137] G. Wu, K.L. More, P. Xu, H.-L. Wang, M. Ferrandon, A.J. Kropf, D.J. Myers, S. Ma, P. Zelenay, Chem. Commun., 49 (2013) 3291-3293.

[138] G. Wu, B.-Q. Xu, J. Power Sources, 174 (2007) 148-158.

[139] Q. Wang, Z.-Y. Zhou, Y.-J. Lai, Y. You, J.-G. Liu, X.-L. Wu, E. Terefe, C. Chen, L. Song, M. Rauf, N. Tian, S.-G. Sun, J. Am. Chem. Soc., 136 (2014) 10882-10885.

[140] H. Furukawa, K.E. Cordova, M. O'Keeffe, O.M. Yaghi, Science, 341 (2013) 1230444.

[141] S. Ma, G.A. Goenaga, A.V. Call, D.-J. Liu, Chem. - A Euro. J., 17 (2011) 2063-2067.

[142] G. Goenaga, S. Ma, S. Yuan, D.-J. Liu, ECS Trans., 33 (2010) 579-586.

[143] E. Proietti, F. Jaouen, M. Lefevre, N. Larouche, J. Tian, J. Herranz, J.-P. Dodelet, Nat. Commun., 2 (2011) 416.

[144] D. Zhao, J.-L. Shui, L.R. Grabstanowicz, C. Chen, S.M. Commet, T. Xu, J. Lu, D.-J. Liu, Adv. Mater., 26 (2014) 1093-1097.

[145] Y. Jiao, Y. Zheng, M. Jaroniec, S.Z. Qiao, Chem. Soc. Rev., 44 (2015) 2060-2086.

[146] W. Chaikittisilp, M. Hu, H. Wang, H.S. Huang, T. Fujita, K.C. Wu, L.C. Chen, Y. Yamauchi, K. Ariga, Chem. Commun., 48 (2012) 7259-7261.

[147] H.-L. Jiang, B. Liu, Y.-Q. Lan, K. Kuratani, T. Akita, H. Shioyama, F. Zong, Q. Xu, J. Am. Chem. Soc., 133 (2011) 11854-11857.

[148] S. Gupta, D. Tryk, I. Bae, W. Aldred, E. Yeager, J Appl Electrochem, 19 (1989) 19-27.

[149] A.L. Bouwkamp-Wijnoltz, W. Visscher, J.A.R. van Veen, E. Boellaard, A.M. van der Kraan, S.C. Tang, J. Phys. Chem. B, 106 (2002) 12993-13001.

[150] J. Masa, W. Xia, M. Muhler, W. Schuhmann, Angew. Chem.-Int. Edit., 54 (2015) 10102-10120.

[151] H. Alt, H. Binder, G. Sandstede, J. Catal., 28 (1973) 8-19.

[152] G. Henrici-Olivé, S. Olivé, Angew. Chem.-Int. Edit., 13 (1974) 29-38.

[153] R. Othman, A.L. Dicks, Z. Zhu, Int. J. Hydrogen Energy, 37 (2012) 357-372.

[154] U. Tylus, Q. Jia, K. Strickland, N. Ramaswamy, A. Serov, P. Atanassov, S. Mukerjee, J. Phys. Chem. C, 118 (2014) 8999-9008.

[155] Q. Jia, N. Ramaswamy, H. Hafiz, U. Tylus, K. Strickland, G. Wu, B. Barbiellini, A. Bansil, E.F. Holby, P. Zelenay, S. Mukerjee, ACS Nano, (2015) DOI: 10.1021/acsnano.1025b05984

[156] E.F. Holby, G. Wu, P. Zelenay, C.D. Taylor, J. Phys. Chem. C, 118 (2014) 14388-14393.

[157] H.-S. Oh, H. Kim, J. Power Sources, 212 (2012) 220-225.

[158] J.P. Dodelet, R. Chenitz, L. Yang, M. Lefèvre, ChemCatChem, 6 (2014) 1866-1867. 
[159] K. Strickland, E. Miner, Q. Jia, U. Tylus, N. Ramaswamy, W. Liang, M.-T. Sougrati, F. Jaouen, S. Mukerjee, Nature communications, 6 (2015).

[160] A. Zitolo, V. Goellner, V. Armel, M.-T. Sougrati, T. Mineva, L. Stievano, E. Fonda, F. Jaouen, Nat. Mater., 14 (2015) 937-942.

[161] N.R. Sahraie, U.I. Kramm, J. Steinberg, Y. Zhang, A. Thomas, T. Reier, J.-P. Paraknowitsch, P. Strasser, Nat. Commun., 6 (2015) 8618.

[162] M. Ferrandona, X. Wang, A.J. Kropfa, D.J. Myersa, G. Wu, C.M. Johnston, P. Zelenay, Electrochim. Acta, 110 (2013) 282-291.

[163] C. Li, G. Wu, E. Holby, P. Zelenay, W. Tao, Q. Kang, Electrochimica Acta, 158 (2015) 175-186.

[164] J. Healy, C. Hayden, T. Xie, K. Olson, R. Waldo, M. Brundage, H. Gasteiger, J. Abbott, Fuel cells, 5 (2005) 302-308.

[165] J. Wu, X.Z. Yuan, J.J. Martin, H. Wang, J. Zhang, J. Shen, S. Wu, W. Merida, J. Power Sources, 184

(2008) 104-119.

[166] A. Serov, K. Artyushkova, E. Niangar, C. Wang, N. Dale, F. Jaouen, M.-T. Sougrati, Q. Jia, S. Mukerjee, P. Atanassov, Nano Energy, 16 (2015) 293-300.

[167] D. Sebastián, V. Baglio, A.S. Aricò, A. Serov, P. Atanassov, Appl. Catal. B: Environ., 182 (2016) 297305.

[168] Y.H. Bing, H.S. Liu, L. Zhang, D. Ghosh, J.J. Zhang, Chem. Soc. Rev., 39 (2010) 2184-2202.

[169] X. Li, S. Park, B.N. Popov, J. Power Sources, 195 (2010) 445-452.

[170] X. Li, H.R. Colón-Mercado, G. Wu, J.-W. Lee, B.N. Popov, Electrochem. Solid-state Lett., 10 (2007) B201-B205.

[171] R. Zhou, S.Z. Qiao, Chem. Mater., 26 (2014) 5868-5873.

[172] G. Cui, P.K. Shen, H. Meng, J. Zhao, G. Wu, J. Power Sources, 196 (2011) 6125-6130.

[173] L. Li, G. Wu, B.-Q. Xu, Carbon, 44 (2006) 2973-2983.

[174] G. Wu, N. Li, D.-R. Zhou, K. Mitsuo, B.-Q. Xu, J. Solid State Chem., 177 (2004) 3682-3692.

[175] J. Zhang, Z. Zhao, Z. Xia, L. Dai, Nat. Nanotechnol., 10 (2015) 444-452.

[176] L. Wang, X. Zhao, Y. Lu, M. Xu, D. Zhang, R.S. Ruoff, K.J. Stevenson, J.B. Goodenough, J.

Electrochem. Soc., 158 (2011) A1379-A1382.

[177] X. Liu, M. Park, M.G. Kim, S. Gupta, X.J. Wang, G. Wu, J. Cho, Nano Energy, (2015)

doi:10.1016/j.nanoen.2015.1011.1030.

[178] X. Liu, W. Liu, M. Ko, S. Chae, S. Park, A. Casimir, G. Wu, J. Cho, Adv. Func. Mater., 25 (2015) 57995808.

[179] X. Liu, M. Park, M.G. Kim, S. Gupta, G. Wu, J. Cho, Angew. Chem.-Int. Edit., 54 (2015) 9654-9658. [180] C.-F. Chen, G. King, R.M. Dickerson, P.A. Papin, S. Gupta, W.R. Kellogg, G. Wu, Nano Energy, 13 (2015) 423-432. 


\section{Graphical abstract:}

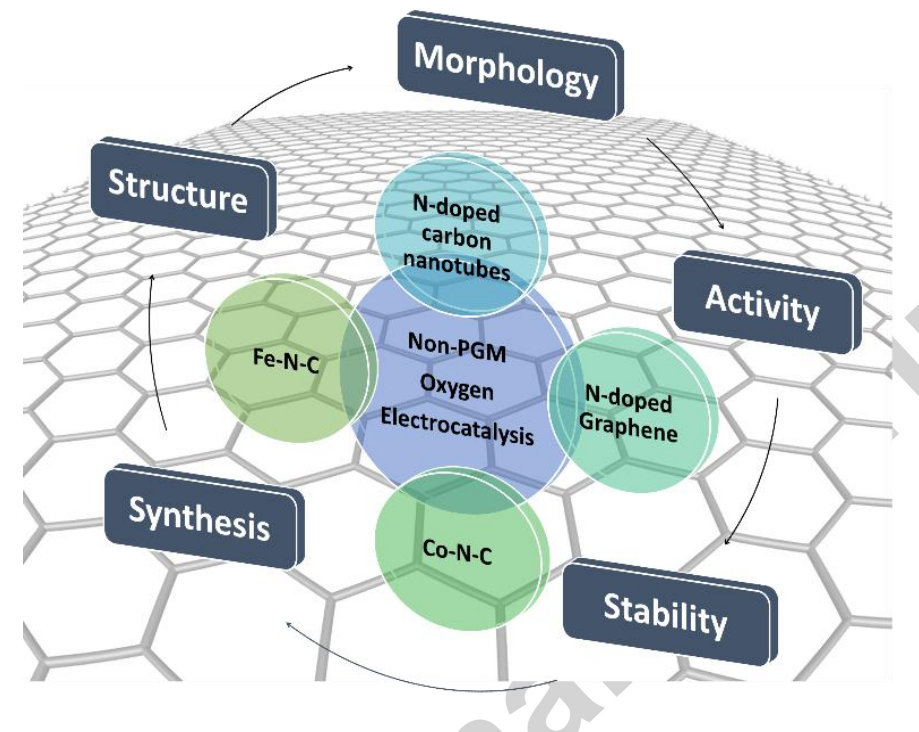

